\title{
Identifying Optimal Irrigation Water Needs at District Scale by Using a Physically Based Agro-Hydrological Model
}

\author{
Antonio Coppola ${ }^{1, *}$, Giovanna Dragonetti ${ }^{2}$, Asma Sengouga ${ }^{2}$, Nicola Lamaddalena ${ }^{2}$, \\ Alessandro Comegna ${ }^{1}\left(\mathbb{D}\right.$, Angelo Basile ${ }^{3}\left(\mathbb{D}\right.$, Nicoletta Noviello ${ }^{4}$ and Luigi Nardella ${ }^{4}$ \\ 1 School of Agricultural, Forestry, Food and Environmental Sciences (SAFE), University of Basilicata, Viale \\ dell'Ateneo Lucano, 10, 85100 Potenza PZ, Italy; antonio.coppola@unibas.it \\ 2 Mediterranean Agronomic Institute, Land and Water Division, IAMB, 70010 Valenzano BA, Italy; \\ dragonetti@iamb.it (G.D.); sengouga@gmail.com (A.S.); lamaddalena@iamb.it (N.L.) \\ 3 Institute of Mediterranean Agriculture and Forestry Systems (ISAFOM), National Council of \\ Research (CNR), 80056 Naples NA, Italy; angelo.basile@cnr.it \\ 4 Consorzio di Bonifica della Capitanata, 71121 Foggia FG, Italy; \\ nicoletta.noviello@bonificacapitanata.it (N.N.); luigi.nardella@bonificacapitanata.it (L.N.) \\ * Correspondence: antonio.coppola@unibas.it; Tel.: +39-0971-206120
}

Received: 10 March 2019; Accepted: 15 April 2019; Published: 21 April 2019

check for updates

\begin{abstract}
This paper mainly aims to illustrate an irrigation management tool to simulate scheduling of district-level water needs over the course of an irrigation season. The tool is mostly based on a daily model for simulating flow of water (and solutes) in heterogeneous agri-environmental systems (called FLOWS-HAGES). The model produces information on the daily evolution of: soil water contents and pressure potentials in the soil profile; water uptake and actual evapotranspiration; stress periods for each crop; return fluxes to the groundwater and their quality in terms of solute concentrations (e.g., nitrates). FLOWS-HAGES provides a daily list of hydrants to be operated according to water or crop-based criteria. The daily optimal sequence of hydrant use may thus be established by passing the volumes to be delivered on to the model for simulating the hydraulics of the irrigation network, in order to ensure that the discharges flowing inside the network of distribution pipes are delivered under optimal pressure head distribution in the system. All the above evaluations can be carried out in a stochastic framework to account for soil heterogeneity and climate changes. To illustrate the potential of FLOWS-HAGES, a case study was considered for a selected sector of the Irrigation District 10 in the "Sinistra Ofanto" irrigation system (southern Italy, Apulia region). In a 139 ha area (Sector 6 of the Irrigation District), soil profiles were analyzed for characterization of hydraulic properties variability. Hydraulic properties were determined by a combination of field and laboratory measurements. Model simulations were validated by comparing soil water storage simulated and measured by a sensor based on electromagnetic induction technique. Irrigation water volumes and frequency calculated by the model were compared to the volumes actually supplied by the farmers. Compared to the farmers behavior, the model simulates more frequent irrigations with lower irrigation volumes. Finally, some indexes of irrigation performance were calculated for each farm under study. The resulting maps provide useful information on the spatial distribution of farmer behavior, indicating the abuse or underuse of water as well as the fraction of the water lost by drainage following the irrigation method applied.
\end{abstract}

Keywords: irrigation; decision support systems; soil water flow modeling; irrigation networks modeling 


\section{Introduction}

Water scarcity and quality degradation are set to become the main environmental problems for all countries in the Mediterranean region in the near future. Due mainly to population growth, pressure on agriculture and demand for water to irrigate food crops have also increased. Indeed, agriculture in Mediterranean countries (apart from those in the eastern Adriatic and France) accounted for $64 \%$ of overall demand in the period 2005-2010 (49\% in the North, $74 \%$ and $81 \%$ in the South and East) [1]. In Mediterranean countries the irrigated area has more than doubled in 40 years, totaling 24,200,000 ha in 2009 (17.8 million in the Mediterranean Europe and 6.4 million in Northern Africa). The growing demand for irrigation water will be mainly met by over-exploiting both renewable and fossil groundwater, prompting seawater intrusion which leads to soil salinization problems in the frequent cases of ineffective irrigation management. Indeed, irrigation is often wasteful and highly inefficient [2]. In an attempt to tackle the problem in Italy and other Mediterranean regions, open-channel irrigation systems have been (or are going to be) converted into pressurized pipeline networks. In most cases, the "on-demand" method for water distribution has been adopted to replace the old rotational schedule.

However, experience shows that even for on-demand pressurized irrigation systems the performance of distribution networks is still frequently far from acceptable in terms of efficiency for both (1) economic/political and (2) technical reasons.

First, even in on-demand irrigation distribution networks, the problem of unmeasured and generally excessive application of irrigation water frequently occurs. This is mostly due to the fact that the price of the water does not reflect the true cost of provision but is kept deliberately low, sometimes for political reasons, by government subsidy. In such cases, the price of irrigation water may be lower than the cost of the labor or equipment needed to avoid over-irrigation, both for the farmer and the distribution network manager. Where water is delivered to the consumer only at fixed times and/or charges are set either per delivery or per hectare regardless of the actual water amount used, farmers tend to take as much water as they can while they can. This generally results in over-irrigation, which wastes both water and nutrients. In some Mediterranean countries the excessive water applied may lead to other serious problems, such as rising water tables, waterlogging and upward movement of salts.

Secondly, in the on-demand framework the manager of the distribution network has little control over water scheduling and hence on the performance of the distribution network. According to the particular combination of farmers who decide to irrigate at a given time (which is not known a priori), the discharges flowing inside the distribution network may change. Under such conditions the actual availability of water resources and the ability of the conveyance hydraulic system may not be able to provide the discharge which the farmers require at a given time. Moreover, under changing (and unknown a priori) discharges, the pressure head in the system can be subject to high fluctuation, with consequent impacts on the efficiency of on-farm irrigation systems [3] also in terms of energy to be spent on water distribution.

The twofold-economic and technical—nature of the problem calls for different kinds of solutions. On the one hand, solutions should come from a change of attitude in managing irrigation water by quantifying the profitability of irrigation water in much the same way as other economic products. In other words, the agricultural sector should seek to maximize the economic return per unit of water (water productivity). On the other hand, irrigation managers should be able to independently assess water demand in relation to the actual availability of water resources and the capability of the conveyance system (a top-down approach). The irrigation managers, provided with appropriate support tools, should be able to determine actual crop water requirements, deciding the optimal timing, quantity and quality of irrigation water to be supplied to the soil in each farm in order to control crop yield, while minimizing deep percolation fluxes of water and nutrients, hence water losses and groundwater degradation.

In this context, the use of decision support systems (DSS) may significantly enhance the management of on-demand irrigation systems. Advanced technical tools are nowadays available for 
monitoring and simulating the various physical processes involved in an irrigation system. Such tools can be used in an integrated way for estimating irrigation water demand and scheduling water use, and thus for simulating the operation of on-demand irrigation networks, under varying soil and weather conditions, crop management options and irrigation technologies.

In general, by integrating the above technical tools with economic instruments, such systems may facilitate the decision-making process on the quantities of water to be allocated to agricultural consumers. Such tools may take into account the most profitable cropping patterns given any water restrictions imposed by existing hydrological conditions, as well as the potential yields in each irrigation district according to its production characteristics, irrigation efficiency, economic scenario and external factors such as agricultural policies.

Against this background, this paper aims to illustrate the application at district scale of a physically-based agro-hydrological model for identifying optimal irrigation water needs in a context of on-demand irrigation systems. The model, called FLOWS-HAGES, simulates district-level water use and scheduling over the course of an irrigation season. The methodology will be applied for sector 6 of Irrigation District 10 in the "Sinistra Ofanto" irrigation system.

The paper is mostly devoted to illustrating the features of the FLOWS-HAGES model. The interaction of this model with a tool simulating the operation of on-demand irrigation networks by the irrigation manager will be the subject of a follow-up paper where, from a technical point of view, the following aspects of irrigation will be solved: spatial and temporal variability of soil water deficit, spatial and temporal variability of farmers' water demand, water resources availability and structural capability of the irrigation conveyance and distribution network.

\section{Materials and Methods}

\subsection{The FLOWS-HAGES Model}

The model simulates water flow and solute transport in heterogeneous agri-environmental systems (termed FLOWS-HAGES). It produces information on the evolution of:

- Soil water contents and pressure potentials in the soil profile;

- Water uptake and actual evapotranspiration (actual water needs);

- Solute (e.g., nitrates, pesticides, salts, heavy metals) concentrations in the soil profile;

- Deep percolation water fluxes (return flow to the groundwater) and their quality in terms of solute (solute fluxes);

- Stress periods for each crop.

The numerical tool is shaped to be run in different configurations and for different purposes:

1. To provide effective water requirement data to be used for optimal management of the irrigation network;

2. To facilitate the decision-making process on the quantities of water to be allocated to agricultural users;

3. To consider the most profitable cropping patterns given water availability restrictions imposed by the existing hydrological systems, and the potential yields reached in each irrigation district according to its productive characteristics, irrigation efficiency, economic scenario and external factors such as agricultural policies;

4. To predict the impact of anticipated climate changes on the irrigation system under the current land use and vegetation cover;

5. To predict the impact of human-driven changes in the land use on the irrigation system under current climate conditions;

6. To predict the impacts on the irrigation system under mixed conditions $4-5$. 
All the evaluations above can also be carried out in a stochastic framework, thus providing uncertainty bands for each of the main outputs.

The numerical code was written in Matlab and is based on a standard finite difference scheme [4-6]. In the model, vertical transient flow is simulated by numerically solving the $1 \mathrm{D}$ form of the Richards equation using an implicit, backward, finite differences scheme with explicit linearization.

The model discretizes the spatial flow field in a prescribed number of nodes (usually 100) of constant width $(\Delta z)$. Time discretization starts with a prescribed initial time increment $(\Delta t)$. This time increment is automatically adjusted at each time level according to the criteria proposed by Vogel [7].

Flow rates and pressure heads, whether constant or variable over time, can be assumed as the upper boundary condition. Gradients of different value, pressure heads or flow rates, again whether constant or variable, can be assumed at the bottom of the soil profile. In this study, daily potential evapotranspiration and rain were assumed at the upper boundary whereas free drainage was assumed at the bottom boundary.

Details on the water and solute transport equations and the sink term calculations are given in the Appendix A. Details of the criteria adopted by the model to control irrigation are reported below.

The criterion used by the model to calculate the time for irrigation and the irrigation volume is schematically summarized in Figure 1a,b.

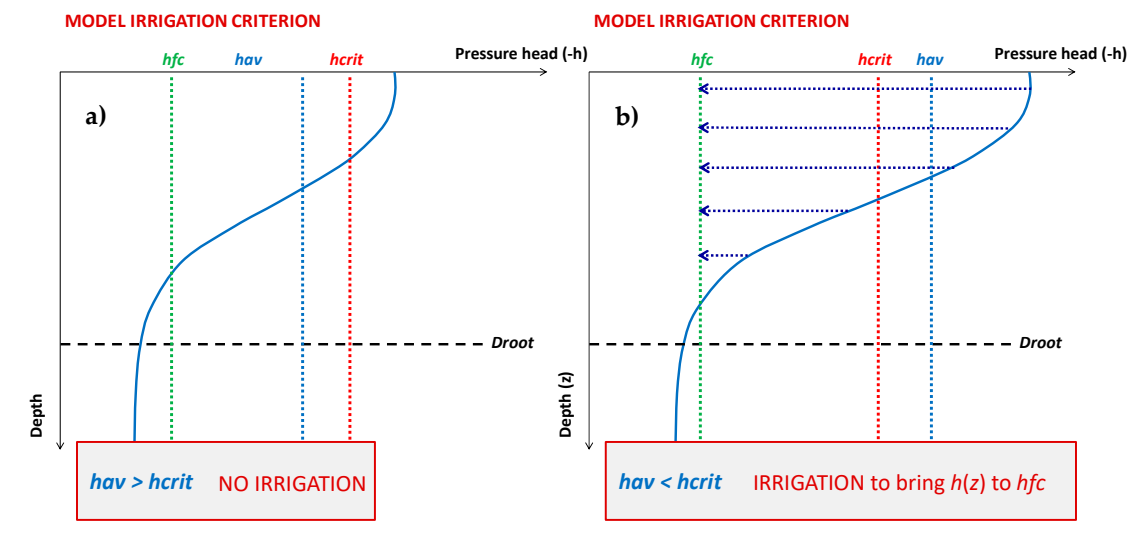

Figure 1. Graphical view of the criterion used by the model to calculate the time for irrigation and the irrigation volume. (a) hav higher than hcrit, no irrigation is required; (b) hav lower than hcrit, irrigation is required to bring the pressure head at the field capacity, $h f c$.

If hav remains higher than hcrit, this means that on average the pressure head $h$ lies above the stress condition and no irrigation is required (Figure 1a). Irrigation starts any time hav becomes lower than hcrit (Figure 1b). In other words, it is assumed that stress starts when the average pressure head in the root zone becomes lower than the threshold for water stress.

The model evaluates the gross irrigation volume to be supplied at day $t$ to the soil profile, Irrgross, as follows:

$$
\operatorname{Irr}_{\text {gross }}=\int_{0}^{\text {Droot }}\left(\theta_{f_{c}}-\theta(z)\right) d z(\mathrm{~cm} \text { of water })
$$

Again, irrigation aims to bring the actual water content at each depth to the water content at field capacity. Figure 2 provides a schematic view of this calculation. Net irrigation, Irr $r_{\text {net }}$, to be supplied on day $t$ is calculated as the difference between $I r r_{\text {gross }}$ and the eventual rain falling at the time when the irrigation starts.

$$
I r r_{\text {net }}=I r r_{\text {gross }}-\text { rainfall }(\mathrm{cm} \text { of water })
$$

If the rainfall exceeds $I r r_{\text {gross }}$, irrigation water is not supplied. 
At the irrigation network management level, the actual irrigation amount $(\mathrm{cm})$, Irract, may be obtained by dividing Irr $r_{n e t}$ by the on-farm irrigation efficiency, IE, of the irrigation system used for the crop considered, to give:

$$
I r r_{a c t}=I r r_{\text {net }} / I E(\mathrm{~cm} \text { of water })
$$

The duration of a hydrant opening, $t_{i r r}$, to satisfy a given $I r r_{a c t}$ at day $t$ is

$$
t_{i r r}=\operatorname{Irr}_{a c t} A k / q
$$

$q$ being the nominal discharge of the hydrant considered $(1 / \mathrm{s}), A$ (ha) the area to be irrigated and $k$ a factor to account for the different dimensions in the equation.

In practice, by repeating the same reasoning for each of the fields included in the irrigation sector, the FLOWS-HAGES model identifies the number, time and position of hydrants to be in operation at day $t$. By aggregating the irrigation demand (the $I r r_{a c t}$ ) for each field in the sector for day $t$, the model calculates the overall discharge to be delivered in that day (the discharge to be delivered at the sector head).

MODEL IRRIGATION CRITERION

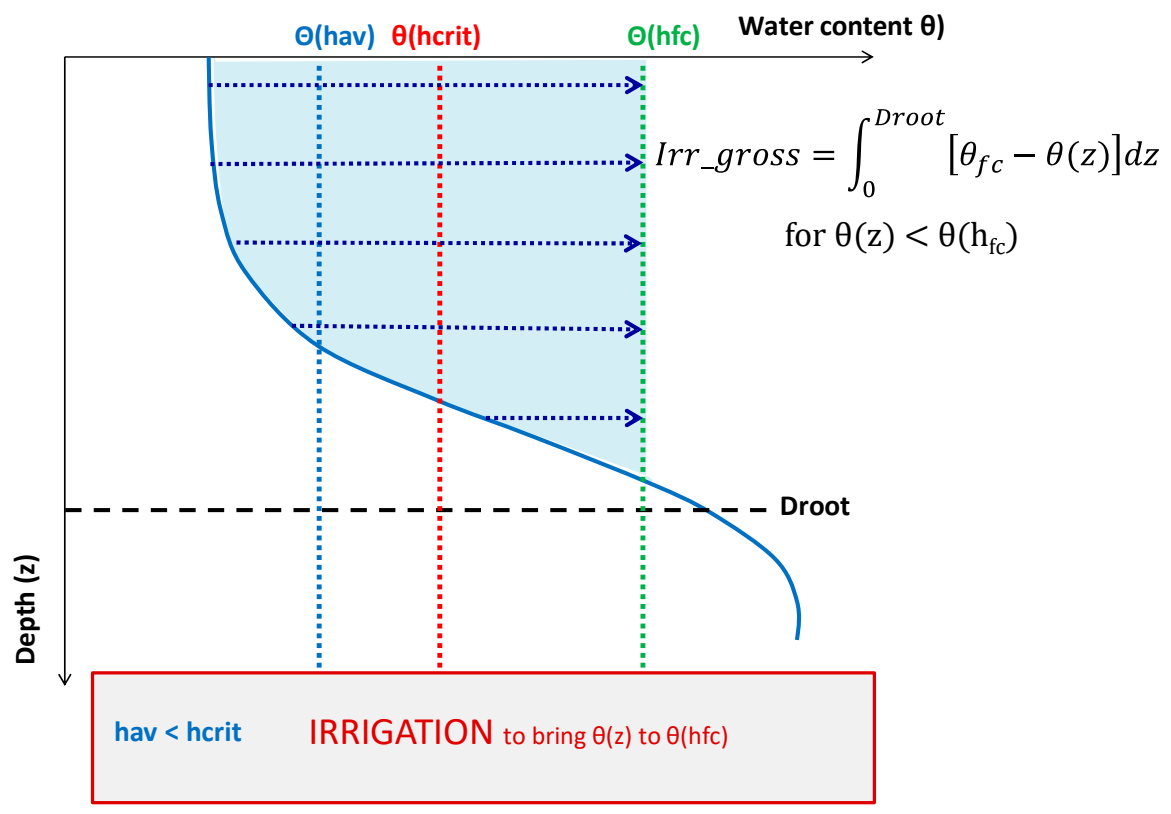

Figure 2. Graphical view of the irrigation volume calculation according to the criterion shown in Figure 1.

\subsection{Sector 6 of the Capitanata Irrigation Network}

The study area belongs to the Capitanata Irrigation Network (in Italian, Consorzio per la Bonifica della Capitanata CBC), Apulia, southern Italy) (Figure 3). The CBC is currently managed by a local water users' organization (WUO), called Consorzio per la Bonifica della Capitanata and covers an area of 22,500 ha. The area is operated with a pressurized on-demand delivery schedule and with a "low zone," where water is supplied to farms by gravity, and a "high zone" where farms are at higher elevations than the water source and irrigation water is conveyed and supplied by a lifting plant. The CBC-low zone consists of seven districts, each sub-divided into smaller operational units ("sectors") consisting of several grouped farms. 


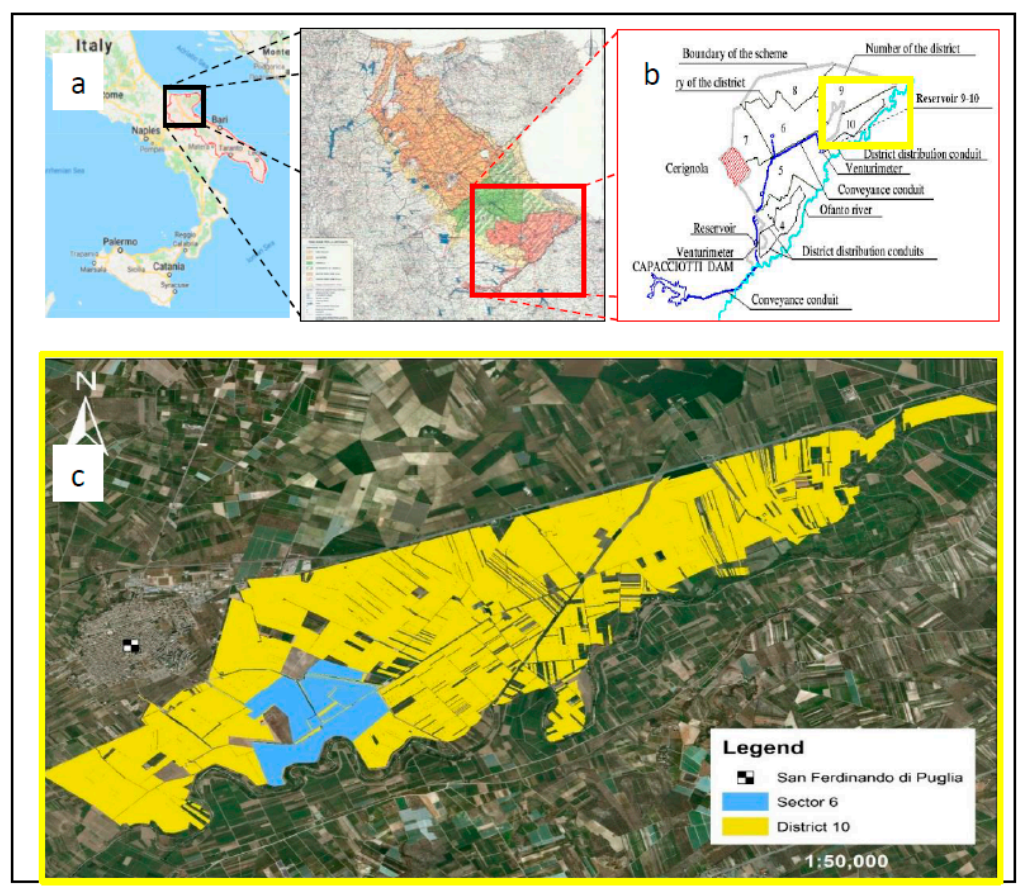

Figure 3. The study area (a). The hydraulic scheme of the low-zone (b). Sector 6 of district 10 in the "Sinistra Ofanto" irrigation system (c).

District 10 of the low zone was specifically considered in this study, covering an overall area of about 2000 ha, of which the total irrigable area is 1679 ha and the area currently irrigated is 1423 ha. Irrigation water comes from a storage and compensation reservoir, with a total capacity of about $50,000 \mathrm{~m}^{3}$, which in turn is supplied with water by the Capacciotti dam. The hydraulic scheme of the low zone is presented in Figure $3 \mathrm{~b}$.

In this paper, the model was applied to Sector 6 (Figure 3c). The latter has an area of 139 ha with an average farm size ranging from 0.5 to $2.5 \mathrm{ha}$. Agriculture in the area is intensive and highly market-oriented. However, the average yearly precipitation in the area is about $550 \mathrm{~mm}$, which is poorly distributed throughout the year. Consequently, intensive farming mostly depends on irrigation.

\subsection{Soil Characterization in Sector 6}

In order to define the pedological and hydraulic characterization of soils, five sites were selected. A pit was dug (Figure 4) for each profile and a pedological description was carried out. For each soil horizon, disturbed soil samples were collected to determine soil texture. Particle-size analysis was carried out using the hydrometer method combined with sieve analysis to characterize the range of particle diameter from 2 up to $2000 \mu \mathrm{m}$ [8]. Sand, silt, and clay contents were expressed as percentages by mass of the fine-soil fraction $(<2 \mathrm{~mm})$ and soil texture was identified according to the United States Department of Agriculture classification (USDA). 

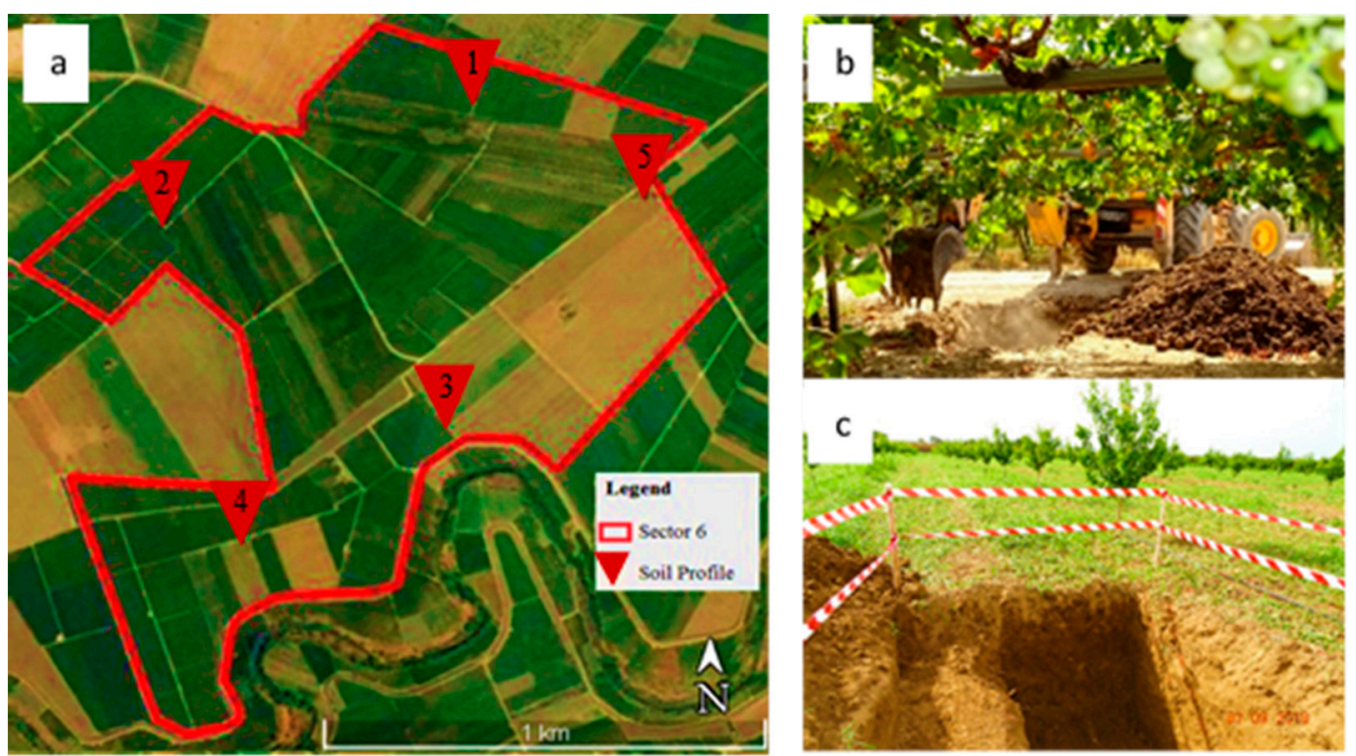

Figure 4. (a) Soil profile distribution; (b) Digging of a soil pit; (c) details of the soil profile vegetation context.

Pedological descriptions and textural data for each soil profile are given in Table 1.

Table 1. Pedological descriptions and textural data for each soil profile.

\begin{tabular}{|c|c|c|c|c|c|}
\hline \multirow{2}{*}{ Profile } & \multirow{2}{*}{ Horizon } & \multicolumn{3}{|c|}{ Texture (\%) } & \multirow{2}{*}{$\begin{array}{l}\text { Texture Class } \\
\text { (USDA) }\end{array}$} \\
\hline & & Sand & Clay & Silt & \\
\hline \multirow{4}{*}{ P1 } & Ap1 & 7.95 & 33.75 & 58.30 & Silty-Clay-Loam \\
\hline & Bw1 & 5.25 & 46.25 & 48.50 & Silty-Clay \\
\hline & Bw2 & 5.75 & 38.75 & 55.50 & Silty-Clay-Loam \\
\hline & Bw3 & 6.63 & 41.25 & 52.13 & Silty-Clay \\
\hline \multirow{4}{*}{$\mathrm{P} 2$} & Ap1 & 27.00 & 18.75 & 54.25 & Silty-Loam \\
\hline & Ap2 & 33.48 & 18.75 & 47.78 & Loam \\
\hline & Bw1 & 34.70 & 21.25 & 44.05 & Loam \\
\hline & Bw2 & 34.90 & 21.25 & 43.85 & Loam \\
\hline \multirow{4}{*}{ P3 } & Ap & 20.45 & 26.25 & 53.30 & Silty-Loam \\
\hline & Bw1 & 20.00 & 26.25 & 53.75 & Silty-Loam \\
\hline & Bw2 & 19.80 & 31.25 & 48.95 & Silty-Clay-Loam \\
\hline & Bw3 & 14.50 & 31.25 & 54.25 & Silty-Clay-Loam \\
\hline \multirow{4}{*}{$\mathrm{P} 4$} & Ap & 32.15 & 21.25 & 46.60 & Loam \\
\hline & $\mathrm{C} 1$ & 35.55 & 18.75 & 45.70 & Loam \\
\hline & $\mathrm{C} 2$ & 40.30 & 18.75 & 40.95 & Loam \\
\hline & CK3 & 39.85 & 18.75 & 41.40 & Loam \\
\hline \multirow{4}{*}{ P5 } & Ap & 25.00 & 33.75 & 41.25 & Clay-Loam \\
\hline & $\mathrm{B} / \mathrm{C}$ & 47.25 & 23.75 & 29.00 & Loam \\
\hline & Bw1 & 28.25 & 33.75 & 38.00 & Clay-Loam \\
\hline & Bw2 & 29.70 & 33.75 & 36.55 & Clay-Loam \\
\hline
\end{tabular}

Hydraulic properties of each horizon for each profile were determined by both field and laboratory methods. As for the shallower horizon, field infiltration measurements were carried out using a tension disc infiltrometer from Soil Measurement Systems (Tucson, AZ) [9-11] with a $20 \mathrm{~cm}$-diameter disc, covered with a highly permeable nylon membrane.

Each sequence of infiltration runs at a given location started with the lowest supply potential, increasing stepwise to the highest. Care was taken when setting up the instrument not to disturb the 
surface on which a thin layer of moist fine sand was applied at each measurement location as a patch with a diameter equal to that of the infiltrometer disc. This smoothed out any irregularities of the soil surface and assured good contact between infiltrometer and soil.

The infiltrometer supply pressure heads were $-10,-7$ and $-4 \mathrm{~cm}$ (water column). For each pressure head, the infiltration test lasted about 13-15 minutes. Before each infiltration measurement, soil samples were taken with steel cylinders near the measurement location to obtain the initial water content. Immediately after each measurement, another sample was collected directly below the infiltration disc to quantify the final water content, as well as bulk density.

In order to deduce simultaneously the water retention and hydraulic conductivity curves from the same infiltration experiment, the transient experimental infiltration data, with initial and final water content, were used for a parameter estimation method based on a numerical solution of the Richards equation [12]. Specifically, in this study, the infiltrometer data were elaborated by the DISC code [13].

At the deeper soil horizons, laboratory hydraulic characterization was carried out on undisturbed soil samples collected by using stainless steel cylinders (inner diameter of $7.6 \mathrm{~cm}$ and height of $7 \mathrm{~cm}$ ). Before performing the hydraulic tests in the laboratory, the height of each core was reduced to the value of $4.0 \mathrm{~cm}$. Each soil core was slowly wetted from below at different steps to obtain the saturation conditions. We then measured water content $\theta_{\mathrm{s}}$ at $h=0$ by the gravimetric method and hydraulic conductivity $K_{s}$ at $\theta_{\mathrm{s}}$ by the falling-head method [14]. The $\theta(h)$ data points were measured using a sand-kaolin suction table. Water retentions were obtained at the following pressure heads: 1.0, 3.0, 7.0, $10.0,15.0,30.0,70.0,90.0,130.0$ and $180.0 \mathrm{~cm}$ (referring to the middle of the sample). We assumed that the average water contents actually corresponded to the indicated pressure head values [15].

The disturbed uppermost part of each soil core was also used to determine the water content $\theta$ at $h$ values of 30,60 and $120 \mathrm{~m}$ by the pressure membrane apparatus. The hydraulic properties measured in the five soil profiles were extended to all the fields in sector 6 by using a simple Thiessen polygon technique.

\subsection{Crop Distribution and Actual Irrigation Volumes (Year 2016)}

The most important species grown in sector 6 are grapevines, peaches and cereals. Figure 5 shows the cultivated area and relative spatial distribution for the year 2016 (data were obtained from CBC). Vineyards cover almost half $(46 \%)$ the total study area; fruit trees with mainly early peach account for one fifth of the total area $(21 \%)$; table grapes, apricots and olives are present in a smaller fraction (2\%).

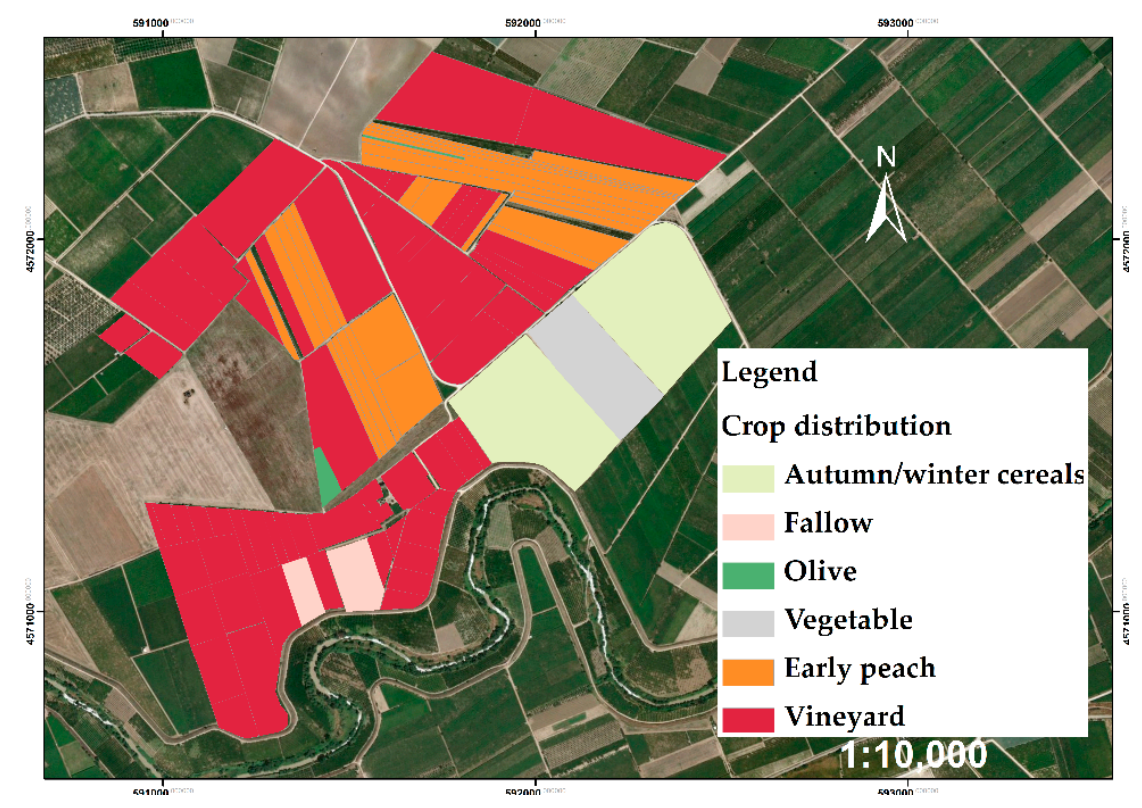

Figure 5. Cropping pattern map of Sector 6 of District 10 in the "Sinistra Ofanto". 
From the recorded volumes in Sector 6 at hydrant level for the year 2016, the total water consumption of farmers was about $125,000 \mathrm{~m}^{3}$. The distribution network of Sector 6 supplies water to 31 delivery hydrants, and covers a total cultivated area of 129 ha, of which 64 ha of vineyards consumed, according to CBC, more than 73,000 $\mathrm{m}^{3}$ in 2016 (Table 2).

Table 2. Crop water consumption for the year 2016 (Source: CBC).

\begin{tabular}{cccc}
\hline Crop & Area $(\mathbf{h a})$ & $\begin{array}{c}\text { Water Consumption } \\
\left(\mathbf{m}^{\mathbf{3}} \mathbf{)}(\text { Year } \mathbf{2 0 1 6})\right.\end{array}$ & $\begin{array}{c}\text { Water Consumption } \\
\mathbf{( \% )}\end{array}$ \\
\hline Vineyard & 64 & $73,640.3$ & 60.4 \\
Early peach & 30 & $46,320.7$ & 38 \\
Autumn winter cereals & 20 & $\mathrm{~N} / \mathrm{A}$ & $\mathrm{N} / \mathrm{A}$ \\
Vegetable & 6.5 & $\mathrm{~N} / \mathrm{A}$ & $\mathrm{N} / \mathrm{A}$ \\
Fallow & 5 & $\mathrm{~N} / \mathrm{A}$ & $\mathrm{N} / \mathrm{A}$ \\
Table Grape & 1 & 732.3 & 0.6 \\
Apricot & 1 & 1163.7 & 1 \\
Olive & 1 & N/A & N/A \\
\hline
\end{tabular}

However, the 30 ha of peach trees consumed more than $46,000 \mathrm{~m}^{3}$, amounting to $38 \%$ of total water consumption. N/A means Not Available

\subsection{Evaluating Model Simulations by Direct Water Content Measurements}

Model simulation reliability was evaluated by comparing simulation results with water storage monitored in the root zone in selected fields of the district by a proximal sensor based on the electromagnetic induction technique (EMI). EMI proximal sensors allow extensive surveys [16]. The EMI sensors measure depth-weighted electrical conductivity (the so-called apparent electrical conductivity, ECa), integrated up to a soil depth depending on both the type of sensor used and the configuration of the sensor coils. ECa depends on the soil profile distribution of water electrical conductivity, $\sigma_{\mathrm{w}}$, volumetric water content, $\theta$, tortuosity, $\tau$, of the soil pore system, as well as on other factors related to the solid phase such as bulk density, clay content and mineralogy. Consequently, separating the effect of single soil properties (e.g., soil water) on ECa is no simple task (see for example, $[17,18])$. However, in two separate studies, $[19,20]$ found spatial variation in soil water stored within the top 0.5 and $1.7 \mathrm{~m}$ to be highly correlated with the spatial variation in ECa measured with EMI sensors. Similar results were obtained by other authors (see for example, [21]. These studies demonstrated that in soils with low salinity, measurements of soil ECa can be used for estimating soil water stored in the soil profile. Estimating soil water content using ECa readings requires a site-specific calibration relating EMI measurements to simultaneous water contents measured by a different standard reference method. In this sense, the time-dynamics of water storage in the selected fields was measured by a Diviner 2000 (Sentek Pty Ltd, Stepney, South Australia) capacitance sensor. A Diviner access tube was installed in three sites of each field up to a depth of $1 \mathrm{~m}$. The Diviner 2000 is a capacitance device consisting of a single sensor fitted to a square rod which can be lowered in a PVC plastic access tube (5.1-cm "i.d.", 5.6-cm "o.d.") [22].

In the same three calibration sites, the ECa was measured in both horizontal coplanar (HCP) and vertical coplanar (VCP) orientation by a CMD-Miniexplorer (GF Instruments, Brno, Czech Republic). The CMD operates at $30 \mathrm{kHz}$ frequency and has three receiver coils with $0.32,0.71$ and 1.18 distance from the transmitter coil. The sensor has to be rotated $90^{\circ}$ to change the orientation from VCP to HCP. According to the manufacturer, the sensor has an effective depth range of $0.5,1.0$ and $1.8 \mathrm{~m}$ in the HCP model, which is halved $(0.25,0.5$ and $0.9 \mathrm{~m})$ in the VCP mode. Thus, a single measurement allows six different ECa readings, each corresponding to a different depth exploration. Both the water content and ECa measurements were carried out at three times campaigns.

We tested which of the six ECa readings yields the best correlation with the total soil water storage in the $0-1 \mathrm{~m}$ depth soil layer. It was found that the 0.9 for VCP and 1.0 for HCP performed best. 
A simple linear regression accurately predicted the water stored in the profile (average of the three measurement sites in each field) at any time. Once calibrated, the CMD was used to monitor the evolution of the water storage in the root zone $(0-80 \mathrm{~cm})$ averaged over the whole field in a total of 12 monitoring campaigns.

\section{Results and Discussion}

In this paper, the FLOWS-HAGES model was applied twice for each farm: (1) to simulate the dynamics and distribution of water in the soil profile by assuming the irrigation time and volumes actually supplied by the farmer; (2) to simulate the dynamics and distribution of water in the soil profile by assuming that irrigation time and volumes were not decided by the farmer but calculated by the model. Water volume requirements from simulations-assumed to be the optimum-were compared to volumes actually delivered by the consortium, thus allowing an estimation of the irrigation efficiency both at field and district scale. Hereafter, labels MOD and ON-DEM will be used to identify respectively the results of the two simulations. Both simulations were carried out by assuming as natural top boundary conditions the rainfall and evapotranspiration data for the year 2016 recorded by a meteorological station located within the sector considered (data not shown here).

\subsection{Irrigation Volumes Measured and Calculated by the Model}

Figure $6 \mathrm{a}, \mathrm{b}$ shows, respectively, the cumulative irrigation volumes for both grapevines and peaches, the most representative crops in the area. In the figure, the curves represent the irrigation volumes actually supplied by the farmers. The bold red line represents the curve calculated by the model. Changes in the slope of each curve indicate irrigation events.

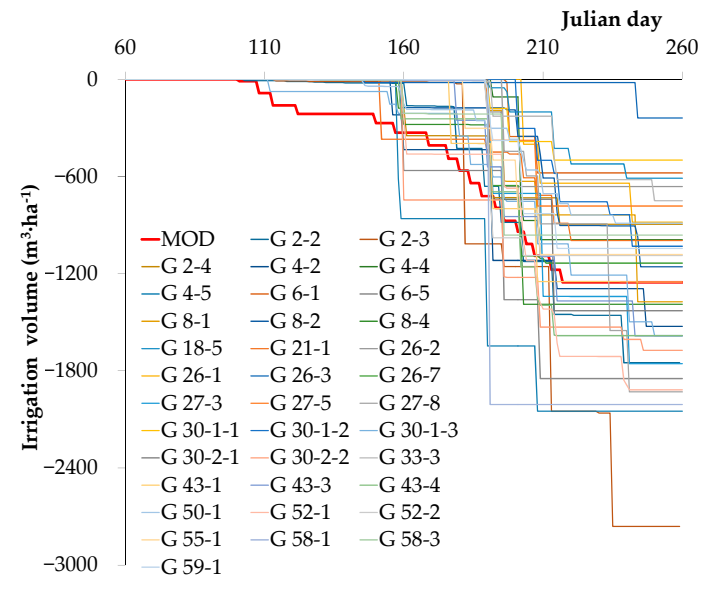

(a)

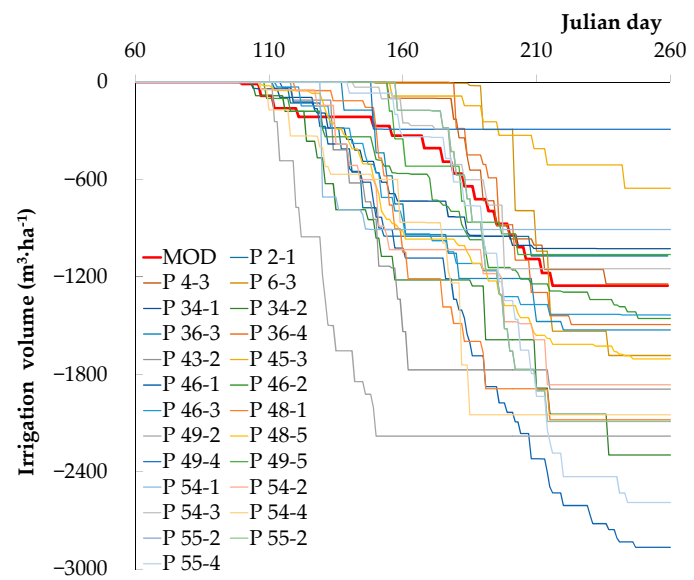

(b)

Figure 6. Cumulative irrigation actually supplied by farmers and calculated by the model (the bold red line) for grape (a) and peach (b).

What is immediately clear from the figures is the large variability in farmer behavior in irrigating the same crop. Besides the lowest volumes, which would suggest a likely use of private farm wells, the large range of cumulative irrigation values indicates that the farmer's experience may be a rather misleading and erratic criterion to establish both the time of irrigation and the irrigation volumes. It is worth noting that the calculated irrigation volumes approximately represent the average behavior of farmers, assuming no variability in soil (or hydraulic behavior) in the irrigation sector.

Further details will be given below for some fields representing both crops, for the case of either lower or higher cumulative irrigation volumes than those calculated by the model. For these selected fields, water storage in the root zone (the $0-80 \mathrm{~cm}$ layer) simulated by the model were compared to those measured by using the EMI sensor. 
Of course, if it is assumed that the model calculates irrigation times and volumes correctly, when the irrigation calculated by the model is lower than that applied by the farmer, this means that the farmer is using more water than necessary. By contrast, if the model estimates the need for more irrigation water than that applied by the farmer, then the farmer is inducing some stress, whose intensity will depend on the water volume actually applied by the farmer.

\subsection{Irrigation Volumes, Pressure Heads in the Root Zone and Deep Percolation Fluxes}

Regarding the grape crop, the farms identified as FARM 2-3-G and FARM 52-1-G were considered in our analysis of the cases of cumulative irrigation volumes lower and higher than those calculated.

The graphs in Figure 7a-d illustrate the irrigation volumes (both per single day and cumulative) calculated by the model (a), the irrigation volumes actually supplied by the farmer (b), the pressure head at $40 \mathrm{~cm}$ depth (c) and the percolation fluxes at $80 \mathrm{~cm}$ (d) for FARM 2-3-G. The depth of $80 \mathrm{~cm}$ was considered as the lowest depth for root uptake. In all the graphs, red and blue lines are used to identify respectively the MOD and ON-DEM simulation results. To demonstrate the goodness of the simulation results, the graph in Figure 7e compares the time evolution of the water storage predicted by the model and that estimated from the EMI sensor ECa readings.
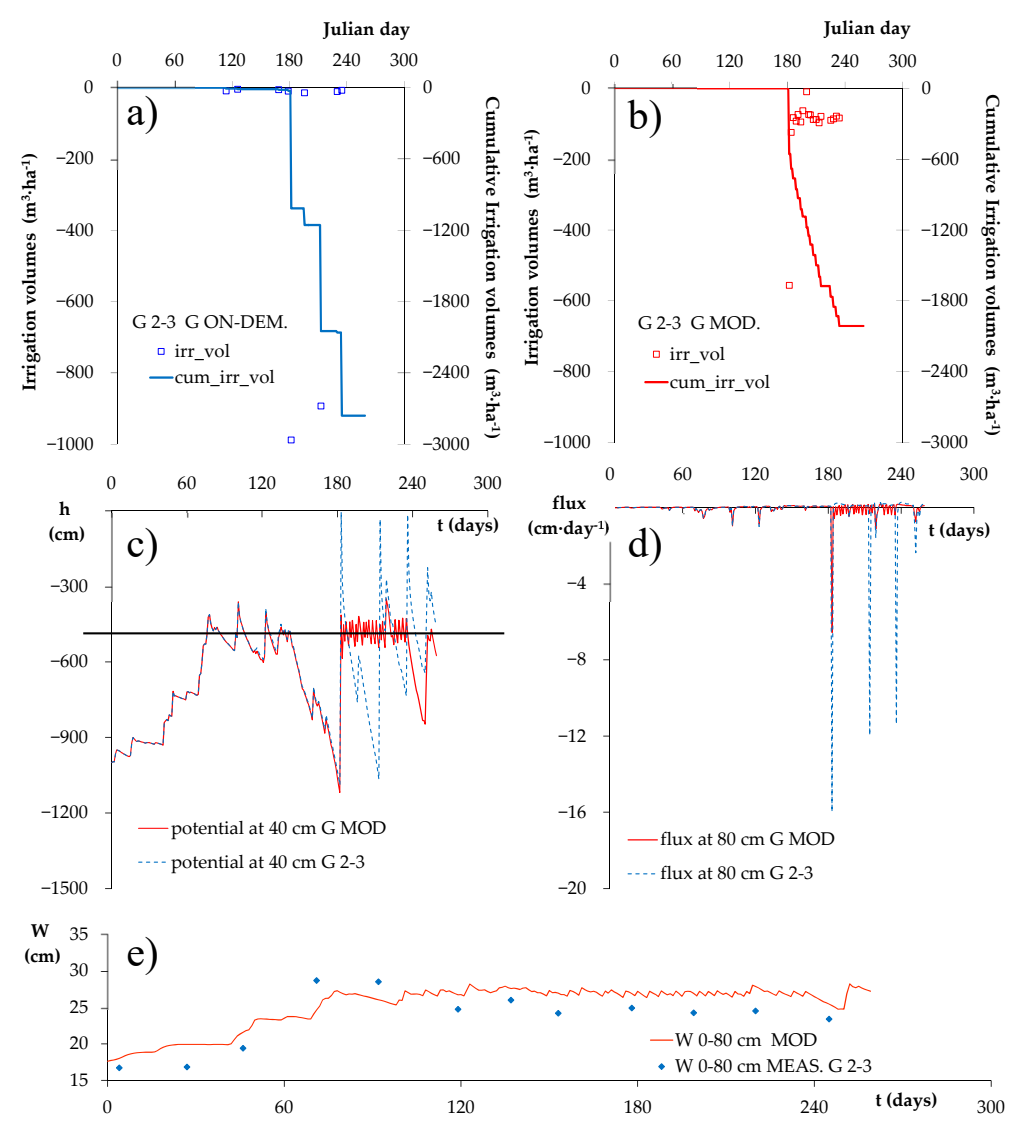

Figure 7. FARM G 2-3. (a) Irrigation volumes (both per single day and cumulative) calculated by the model (MOD); (b) irrigation volumes actually supplied by the farmer (ON-DEM); (c) pressure head at $40 \mathrm{~cm}$ depth; (d) percolation fluxes at $80 \mathrm{~cm}$; (e) comparison between the time evolution of the water storage predicted by the model (MOD) and that estimated starting from the electromagnetic induction technique (EMI) sensor apparent electrical conductivity (ECa) readings (MEAS).

Figure 8a-e shows the same graphs for FARM 52-1-G. 

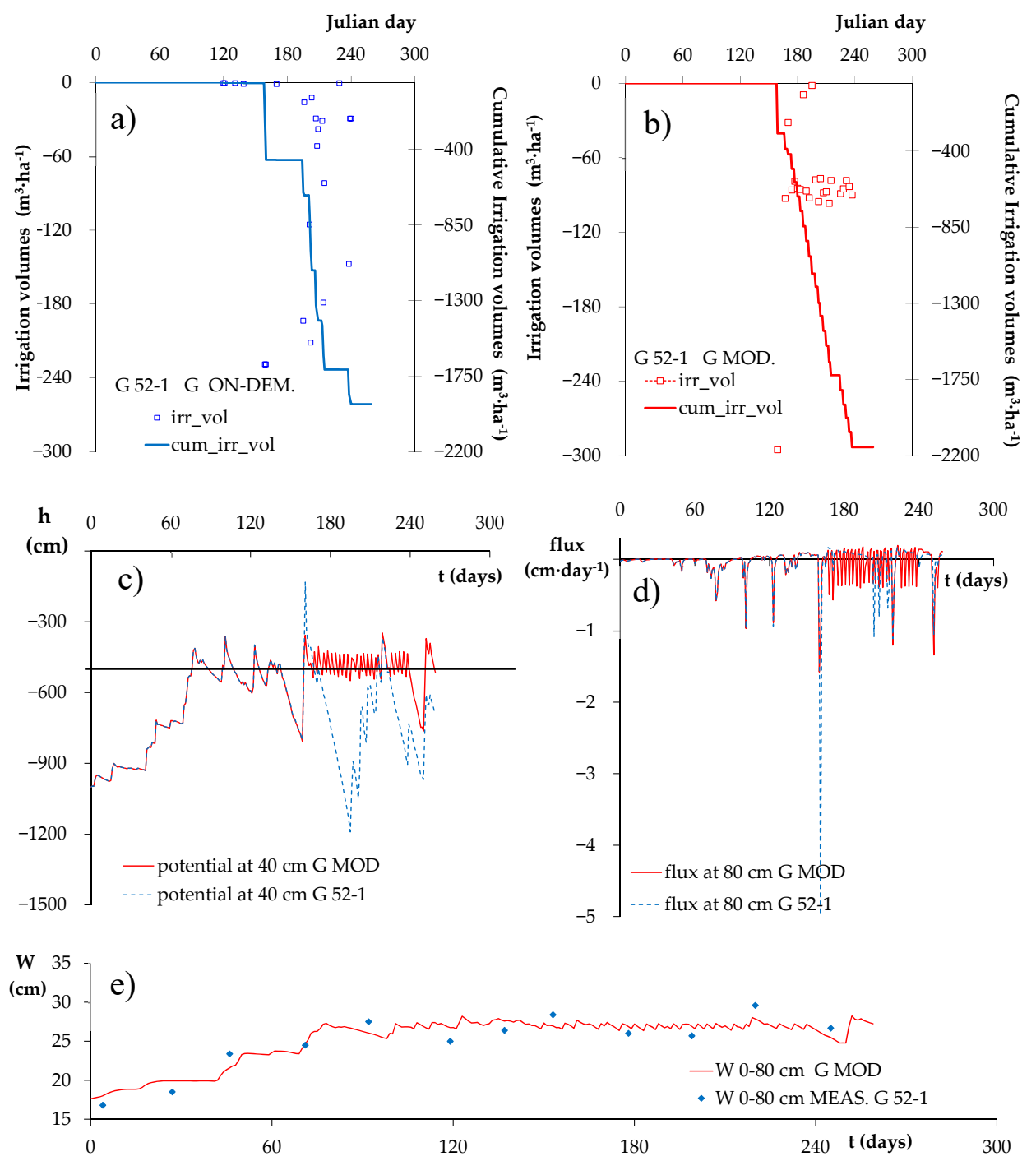

Figure 8. FARM G 52-1. (a) The irrigation volumes (both per single day and cumulative) calculated by the model (MOD); (b) the irrigation volumes actually supplied by the farmer (ON-DEM); (c) the pressure head at $40 \mathrm{~cm}$ depth; (d) the percolation fluxes at $80 \mathrm{~cm}$; (e) comparison between the time evolution of the water storage predicted by the model (MOD) and that estimated starting from the EMI sensor ECa readings (MEAS).

As for the peach crop, the farms identified as FARM 54-4-P and as FARM 49-5-P will be considered to analyze the cases of cumulative irrigation volumes lower and larger than the calculated ones. Figures 9a-e and 10a-e show the graphs for the FARM 54-4-P and the FARM 49-5-P, respectively.

Irrespective of whether the farmer supplied more or less than the irrigation volumes calculated by the model, compared to the farmer, the model "would irrigate" more frequently with lower volumes. 


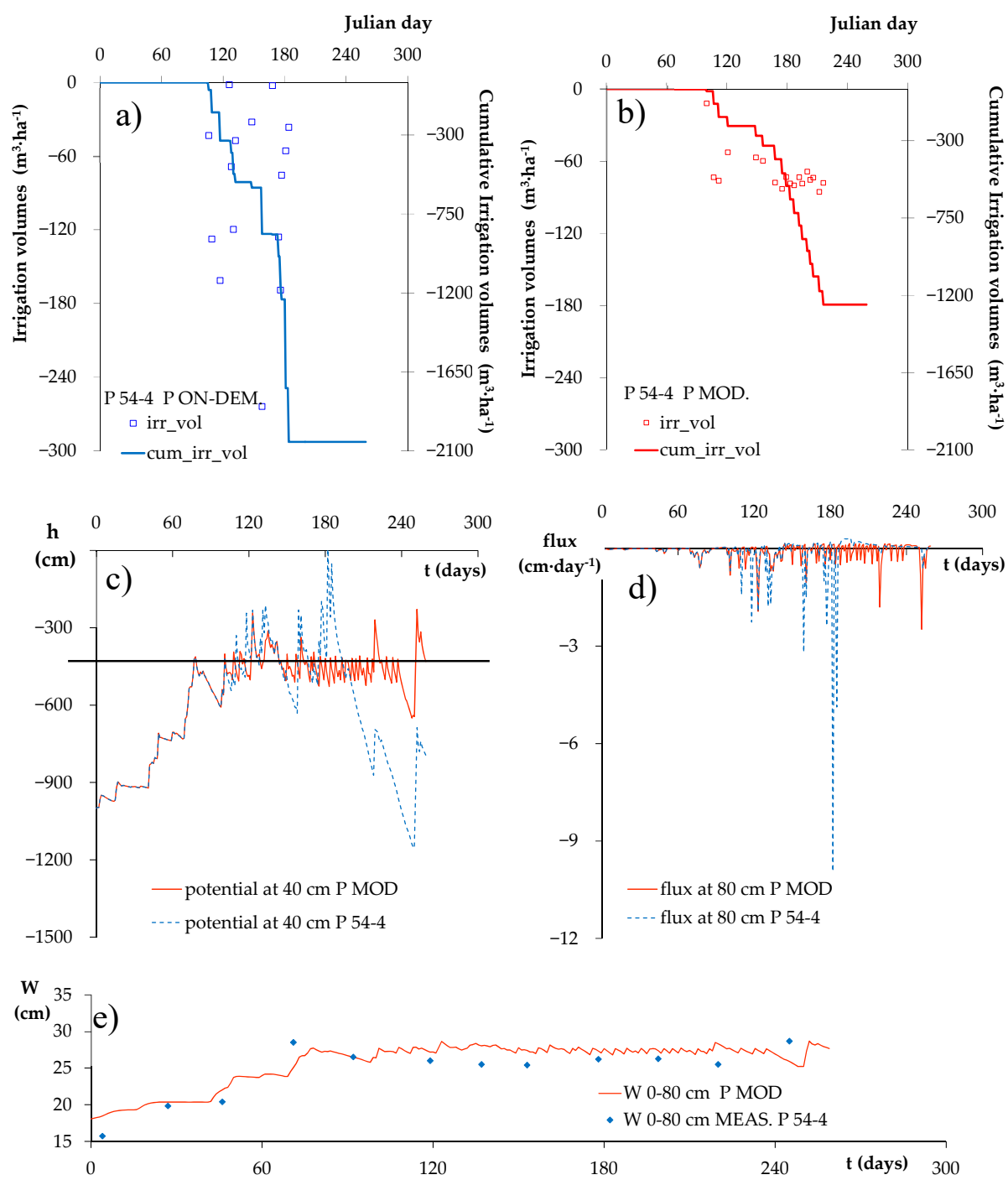

Figure 9. FARM P 54-4. (a) The irrigation volumes (both per single day and cumulative) calculated by the model (MOD.); (b) the irrigation volumes actually supplied by the farmer (ON-DEM); (c) the pressure head at $40 \mathrm{~cm}$ depth; (d) the percolation fluxes at $80 \mathrm{~cm}$; (e) comparison between the time evolution of the water storage predicted by the model (MOD) and that estimated starting from the EMI sensor ECa readings (MEAS).

In the graph of pressure heads, the horizontal line indicates the critical pressure head (hcrit) selected for the grape crop. It is interesting to see how the model allows the pressure head to remain regularly above the critical value, with frequent irrigation and low volumes applied. The low volumes have major implications in terms of overall discharge to be supplied at the head of the irrigation sector.

The MOD deep percolation fluxes may be either higher or lower than the ON-DEM, depending on the value of the cumulative irrigation volumes calculated by the model or actually supplied by the farmer. However, no general rule exists. For example, in the case of FARM 52-1-G, MOD irrigation volumes are higher than ON-DEM volumes, and yet deep percolation fluxes are comparable to those of ON-DEM. This may be explained by the fact that the farmer irrigates less frequently with higher volumes. This induces stress periods alternating with relatively large irrigation supplies, the latter leading to higher water contents (higher than the field capacity) and hence higher downward water fluxes due to the higher hydraulic conductivity. 

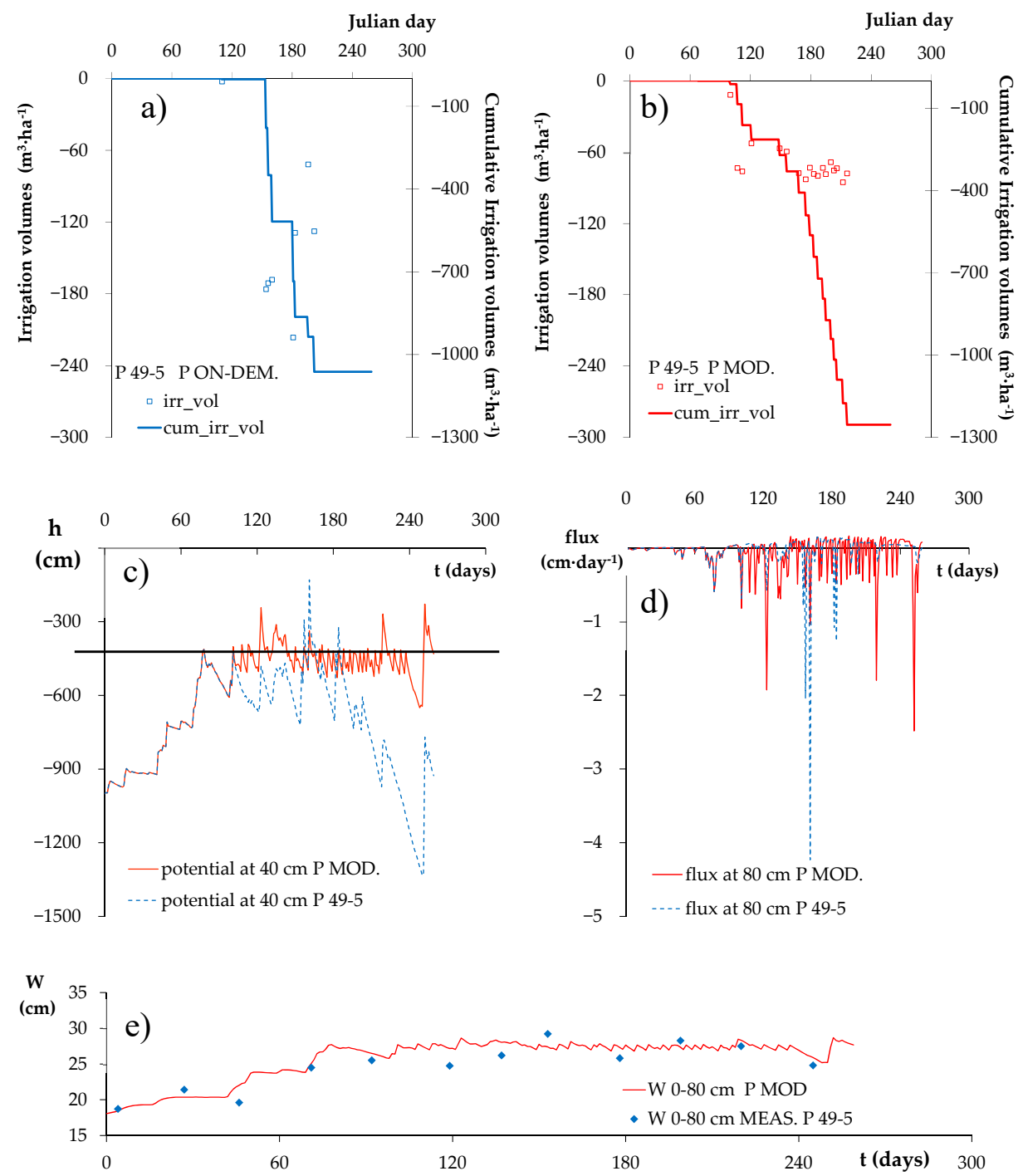

Figure 10. FARM P 49-5. (a) Irrigation volumes (both per single day and cumulative) calculated by the model (MOD); (b) irrigation volumes actually supplied by the farmer (ON-DEM); (c) the pressure head at $40 \mathrm{~cm}$ depth; (d) the percolation fluxes at $80 \mathrm{~cm}$; (e) comparison between the time evolution of the water storage predicted by the model (MOD) and that estimated starting from the EMI sensor ECa readings (MEAS).

\subsection{List of Hydrants to be Opened and Efficiency Indices}

The above discussion concerning some representative fields may be extended to the whole set of fields considered in the irrigation sector. The final result is the list of hydrants to be opened day by day during the growing season of a crop, along with irrigation volumes. Table 3 reports this list for the grape crop. 
Table 3. List of hydrants to be opened day by day and volumes $\left(\mathrm{m}^{3}\right)$ to be supplied during the growing season for grape (year 2016).

\begin{tabular}{|c|c|c|c|c|c|c|c|c|c|c|c|c|c|c|c|c|c|c|c|c|c|c|c|c|c|c|c|c|c|c|c|c|c|c|c|c|}
\hline 111 & G 2-2 & G2-3 & G $2-4$ & G4.2 & G $4-4$ & G 4.5 & $G^{6-1}$ & G 6.5 & G 8-1 & G 8-2 & G 8-4 & G 18-5 & G21-1 & $G_{2} 26-1$ & G 26-2 & $G 26-3$ & G 26-7 & G 27-3 & $\mathrm{G} 27.5$ & $\mathrm{G} 272.8 \mathrm{G}$ & G 30-1-1 G & G $30-1-25$ & 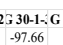 & $\mathrm{G} 30-2-1 \mathrm{C}$ & G 30-2-2 & G 33-3 & G 43-1 & G G 43-3 & & G 50-1 & G 52-1 & G 52-2 & G $55-1$ & G 58-1 & G 58.3 & \\
\hline & & & & & & & & & & & & & & & & & & & & & & & $\begin{array}{l}-72.91 \\
-71.46\end{array}$ & & & & & & & & & & & & & \\
\hline 146 & & & & & & & & & & & & & & & & -99.95 & & & & & & & -79.27 & & & & & & & -99.95 & & & & & & \\
\hline $\begin{array}{l}158 \\
151\end{array}$ & & & & & & & & & & & & & - 193.44 & & & $\begin{array}{l}-7.4 .85 \\
-75.115 \\
\end{array}$ & & & & & & & & & & & & & & $\begin{array}{l}-77.85 \\
-7.115\end{array}$ & & & & & & \\
\hline 155 & & & & -239.87 & & & & & & & & & & & & & & & & & & & -76.58 & & & & & & & & & & & & & \\
\hline 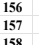 & & & & & & -263.7 & & & & 2867 & -263.7 & & & & & -81.715 & & & & & & & & & & & & & & .81.715 & & & & & & \\
\hline 159 & & & -295.3 & .89 .99 & & & & -295.3 & & -28.67 & & & & & & & & & & & & & -74.34 & -295.3 & & & & & -28.67 & & -295.3 & & & & & \\
\hline 163 & $\begin{array}{l}-252.33 \\
-78.235\end{array}$ & & & & & & & & & & & & & & & & & & & & & & & & & & & & & & & & & & & \\
\hline 167 & -78.295 & & -92.685 & -8.3585 & & -79.165 & & -92.685 & & 1,300 & -79.165 & & -79.335 & & & & & & & & & & - $72.6-9$ & -92.685 & & & & & 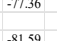 & & -92.685 & & & & & \\
\hline 1770 & -86.345 & & $\begin{array}{l}-31.56 \\
-859975 \\
\end{array}$ & $\begin{array}{r}-28.59 \\
-844265\end{array}$ & & $\begin{array}{l}-27.14 \\
-83.765\end{array}$ & & $\begin{array}{r}-31.56 \\
-859975 \\
\end{array}$ & & -76.24 & $\begin{array}{l}-27.14 \\
.837765\end{array}$ & & $\begin{array}{l}-26.885 \\
-28335\end{array}$ & & & -84.561 & & & & & & & $-232.28=$ & $\begin{array}{l}-81.56 \\
-8.5975\end{array}$ & & & & & . 8.1 .79 & & $\begin{array}{l}-31.56 \\
-8.59975\end{array}$ & & & & & \\
\hline $\begin{array}{l}1176 \\
177\end{array}$ & .79 .65 & & .78 .88 & .78 .35 & & -77.815 & & .78 .88 & & -76.58 &.-77.815 & & -77.655 & & & .78 .31 & & & & & & & $-75.33-4$ & .78 .88 & & & -414.58 & & & .78 .351 & -7888 & & & & & \\
\hline 180 & .85 .9 & & -84.585 & .84 .15 & & -83.585 & & -84.585 & & .82 .92 & .83 .585 & & -83.435 & & & .83 .61 & & & & & & & $-81.3-8$ & .84 .585 & & & $\begin{array}{l}-16.955 \\
-7755 \\
-175\end{array}$ & $\begin{array}{r}-457.68 \\
-1176.68\end{array}$ & .8292 & .83 .61 & -84.585 & & & & & \\
\hline 1. 1828 & & -555.88 & & & & & & & & & & & & & & & & & & & & & & & & & & 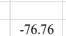 & & & & & .533.49 & & & \\
\hline 18184 & 85.66 & $\begin{array}{l}-124.6 \\
\end{array}$ & -85.5 & -85.2 & & -84.745 & & -85.5 & & -84.79 & $.84,745$ & & -84.86 & & & 85.16 & & & & & & & -82.9 & -85.5 & & & & & 84.79 & -85.16 & -85.5 & & - 121.16 & & & \\
\hline 186 & & -82.24 & & & & & & & & -89.92 & & & & & & & & & & & & & -8.55 & & & & 94.825 & 6 & -89.92 & & & & .7285 & & & \\
\hline 189 & .86 .941 & -92.51 & 86.78 & -86.28 & & $\begin{array}{r}86.47 \\
\end{array}$ & & -86.78 & -72.815 & .86 .65 & -86.47 & -728.55 & .86 .25 & & -728.55 & -86.365 & & & .728 .55 & & . 728.55 & & -84.94 & -86.78 & & -728.55 & & & 86.65. & -86.365 & -86.78 & -728.55 & & -728.55 & & - 728.55 \\
\hline 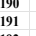 & & $\begin{array}{l}-73.72 \\
\end{array}$ & & & -781.23 & & & & & & & -143.12 & & & -143.12 & & - -754.49 & - -53.49 & - 143.12 & & . 143.12 & & & & & - 143.12 & & -95.52 & & & & -143.12 & & & & -143.12 \\
\hline 193 & $-92,335$ & & -9225 & -91.941 & -145.35 & -91.671 & & -9225 & -84.175 & -91.98 & -91.671 & -84.47 & -91.321 & & .8447 & -99.143 & -143.89 & - 14.8 .89 & -8447 & & .84 .47 & & 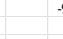 & -9225 & & -84.47 & .94 .475 & & -91.98 & -91.43 & -92.25 & 8447 & -944695 & & & -84.47 \\
\hline 190 & & -94.55 & & & -92.775 & & & & .76 .55 & & & .82 .9 & & & & & 8 & 80.539 & -82.9 & .892 .25 & .82 .9 & & -98.97 & & & .82 .9 & . -3.451 & -96.561 & & & & .829 & .79 .95 & & & .82 .9 \\
\hline 1960 & & -63.3 & & & & & $\begin{array}{r}-49.93 \\
-123.23 \\
\end{array}$ & & -624455 & & & & & & & & -66.583 & -66.588 & & & & & & & & & -59.375 & -63.32 & & & & & & & & \\
\hline 199 & -77.74 & & -77.71 & -77.315 & -85.281 & -77.421 & .81 .585 & -77.71 & -92.22 & -77.65 & - 77.421 & & -77.45 & & & -77.29 & -95.4 & -95.4 & & -99.445 & & -969.48 & -76.16 & -77.71 & & & .88 .83 & & -77.65 & -77.29 & - 77.71 & & -76.655 & & & \\
\hline 202 & -95.165 & -73.335 & $\begin{array}{l}-95.27 \\
\end{array}$ & -95.85 & $\begin{array}{l}-7.59 \\
7.635\end{array}$ & -94.77 & -76.84 & $\begin{array}{l}-95.27 \\
\end{array}$ & -74.75 & -94.89 & & -73.455 & -94.875 & -122.53 & & .94,79 & -75.255 & -75.255 & 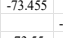 & $-78.295^{\circ}$ & $\begin{array}{l}-73.455 \\
.\end{array}$ & -159.97. & $-93,62$ & -95.27 & & -73.455 & -72.255 . & -73.115 & -94.89 & .94 .79 & -95.27 & 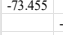 & .96 .675 & & & -73.455 \\
\hline 204 & -77.251 & $\begin{array}{l}-74.85 \\
\end{array}$ & $.76,775$ &.-77.4 & - -74.635 & -76.62 & -77.9 &.-76.775 & .74 .875 & -76.66 & & .73.55 & -76.685 & -166.77 & & .76 .87 & -.75 .615 & -75.615 & & -77.641 & - & -944441 & $-75.82-7$ & -76.775 & & -73.55 & -73.82 & -73.98 & -76.66 & -76.87 & -76.775 & & -77.335 & & & -73.55 \\
\hline 207 & .88 .185 & -87.671 & -88235 & -87.675 & & & & .882235 & -88.765 & .88 .45 & & -953.15 & -87.641 & & & .87985 & -89.651 & -89.651 & & -91.25 & & & -8 & -88.235 & & & & -87.53 & .88 .45 & -87.985 & -88.235 & & -89.2 & & & -95.315 \\
\hline & & & & & & & & & & & & .92331 & & -72.891 & & & & & & -72.325 & -922391 & -94.8 & & & & -92.391 & & & & & & & & & & -923.391 \\
\hline $\begin{array}{l}210 \\
212\end{array}$ & .87 .255 & -87.641 & -87.371 & -87.95 & & & & & -88.431 & .87 .33 & & -91.555 & .86 .335 & & & -86.911 & & .88 .835 & & $-89.661-$ & -91.555 & -94.421 & $-86.16-8$ & -87.371 & -16.39 & -91.555 & & -87.3 & -87.33 & 866911 & -87.371 & & & & & \\
\hline 213 & -96.55 & -96.871 & -9.6 .641 & -96.22 & & & & & -97.395 & -96.15 & & .78 .86 & -96.25 & -76.29 & & -96.185 & & -99.775 & & .78 .885 & & & -9.95.17 & -96.641 & & .78 .86 & & -96.775 & & -96.185 & -96.641 & & & & & \\
\hline $\begin{array}{l}215 \\
216 \\
216\end{array}$ & -78.351 & $\begin{array}{l}-78.79 \\
\end{array}$ & & -78.1 & & & & & -79.51 & -78.21 & & & -78.125 & -77.551 & & -78.28 & & -79.3151 & & & & .732 .24 & -7- 7.75. & .78 .145 & 7645 & & & \begin{tabular}{|l|}
-78.7 \\
\end{tabular} & & -78.28 & -78.145 & & & & - 1295.55 & \\
\hline & & & & & & & & & .5435 & & & -96.98 & & $\begin{array}{l}-72.82 \\
\end{array}$ & & & & -72.465 & & -97.55 & & & & & & -96.98 & & -53485 & & & & & & & $\begin{array}{r}-172285 \\
-547771\end{array}$ & \\
\hline 225 & .89355 & -89.955 & & .88 .635 & & & & & & .88 .91 & & -76.3 & & -.77 .375 & & -88.655 & & -75.5 & & -77.21 & & -83.97 & $86.59-8$ & -88.935 & 88.5 & -76.3 & & -7605 & & -88.655 & -88.935 & & & & 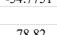 & \\
\hline 228 & .84941 & $\begin{array}{l}-85.76 \\
\end{array}$ & & $\begin{array}{l}-84.78 \\
\end{array}$ & & & & & 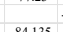 & -84.92 & & -81.245 & & -82.3 & & .84 .815 & & & & -81911 & & -84.25 & -83.68 & -85 & -85.941 & -81.245 & & -10.0880 & & -84.815 & .85 & & & & -18.82 & \\
\hline 231 & .78.36 & - 78.635 & & .78 .25 & & & & & 84.130 & -.78 .8 & & $\begin{array}{r}-76.78 \\
\end{array}$ & & -77.125 & & - 77.855 & & $\begin{array}{l}-76.585 \\
\end{array}$ & & -78 & & -78.171 & - 77.18 & -78.325 & -79.21 & -76.78 & & -83.860 & & -77.855 & $\begin{array}{l}-78.325 \\
\end{array}$ & & & & -85.595 & \\
\hline 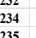 & .83 .2 & .83 .77 & & .82 .99 & & & & & - & .82 .84 & & .82 .53 & & .8279 & & -83.125 & & .82 .225 & & .82 .615 & & -83.411 & -82.95 & -83.18 & -84.7 & .82 .53 & & -75.685 & & .83 .125 & -83.18 & & & & -77.125 & \\
\hline 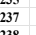 & & & & -89.77 & & & & & . & .89 .78 & & .89 .73 & & -89.865 & & $-89,525$ & & .89 .7 & & -89.782 & & & .88 .76 & -89.87 & & -89.73 & & -8.6995 & & & -89.87 & & & & -83.8 & \\
\hline 24 & & & & .88 .25 & & & & & $\begin{array}{l}-92.6 \\
0.890\end{array}$ & .88 .28 & & & & .88 .455 & & .883355 & & & & & & -88.765 & $-87.43-8$ & -88.131 & -89.15 & -88.15 & & -92.13 & & & & & & & -93.181 & \\
\hline 24 & & & & .83 .762 & & & & & & .83 .88 & & & & & & & & & & & & & 82.74 & -84.4 & & .83 .861 & & -87.41 & & & & & & & -88.475 & \\
\hline & & & & & & & & & & & & & & & & & & & & & & & .78 .98 & & & & & & & & & & & & 8.84 & \\
\hline
\end{tabular}


Based on the modeling results, the following indices may be mapped (see Figure 11a-d).
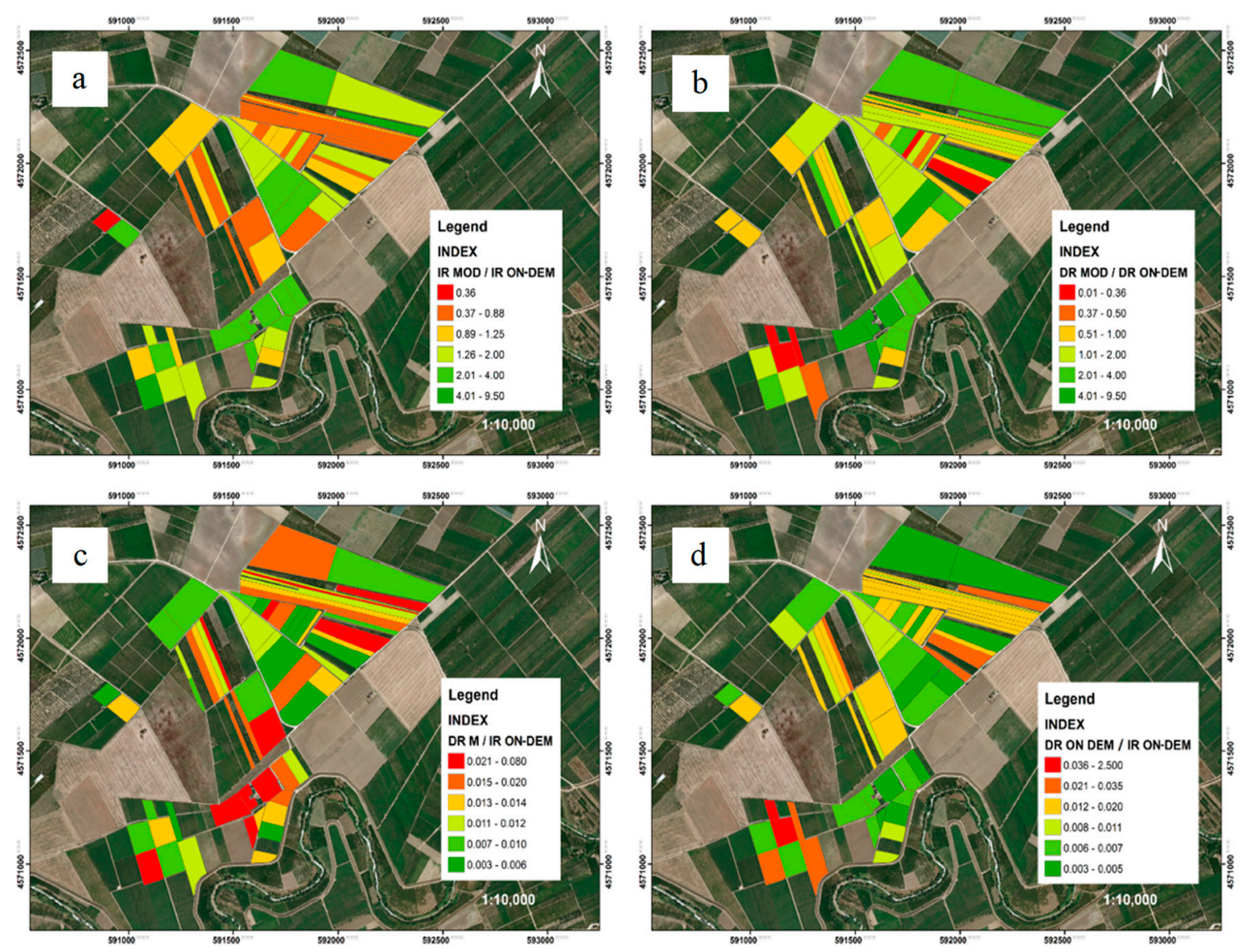

Figure 11. Maps of four indices: (a) Ratio of irrigation volumes model/irrigation volumes on-demand (IR MOD/IR ON-DEM); (b) ratio of drainage volumes model/drainage volumes on-demand (DR MOD/DR ON-DEM); (c) ratio of drainage volumes model/irrigation volumes on-demand (DR MOD/IR ON-DEM); (d) ratio of drainage volumes on-demand/irrigation volumes on-demand (DR ON-DEM/IR ON-DEM).

1. Ratio of irrigation volumes model/irrigation volumes on-demand: A value $>1$ indicates that the irrigation volumes modeled exceed those supplied by the farmer. If it is assumed that the model calculates irrigation volumes correctly, this means that the farmer is causing some stress, which may have an impact on crop yield. By contrast, a value $<1$ means higher volumes applied by the farmer, thus indicating that the farmer is using more water than necessary and is causing undue water (and nutrient) losses.

2. Ratio of drainage volumes model/drainage volumes on-demand: this index gives a measure of the deep percolation fluxes in the case of MOD irrigation volumes compared to ON-DEM. The index tends to follow the same pattern as the first. However, this cannot be generalized as there are fields where considerable MOD irrigation volumes result in MOD deep percolation fluxes which are somewhat greater than those of ON-DEM, due to the higher irrigation frequency and lower volumes applied in the MOD case. In other words, this means that when the model calculates the irrigation volumes, the water content in the root zone is maintained low enough to keep the hydraulic conductivity low, thus reducing the fluxes downward. However, the water content is kept stably above the critical pressure head so that the crop can stably uptake the optimal amount of water without stress.

The last two indices give information on the fraction of the water lost by percolation fluxes below the root zone in the MOD and ON-DEM cases, respectively. Interestingly, in general with the MOD irrigation system, a lower fraction of water is lost to drainage. In other words, of the water applied, a larger part remains in the root zone available for root uptake. This is what is commonly called 
application efficiency, which is evidently related to the frequency of irrigation and volumes applied for each irrigation, an issue extensively discussed above.

\section{Conclusions}

The main objective of this paper was to describe the potential of an irrigation management tool to simulate district-level water use and scheduling over the course of an irrigation season. The tool is largely based on the use of mathematical models for the simulation of soil water movement in the unsaturated zone. This is a precise approach to rational irrigation and the key to saving irrigation water. Compared to other similar existing approaches, the soil water balance is calculated by solving the partial differential equation known as the Richards equation. Additionally, the tool takes into account the spatial variability of the soil hydraulic parameters.

The combination of a detailed mathematical model, which solves the Richards equation, with some method of handling the spatial variability is highly desired. In this sense, the model provides a way to establish the right frequency and amount of irrigation to keep the pressure head above the critical value by minimizing both the stress periods and the water (and nutrients) lost by deep percolation fluxes.

The tool, due to its increased requirements in specialized data, is not aimed at the farmer but rather at an organization that could provide irrigation advisory services to farmers. It is designed to support farmers in improving irrigation management at the farm scale.

The tool responds to the question of balancing the pressure from growing water demands and the need to increase agricultural resilience to climate change through irrigation. Reducing water losses in the agricultural sector, by far the biggest water consumer, is probably the single most important step toward a more efficient management of water resources. To achieve this goal, the first step is undoubtedly to empower managers and through them the farmers.

Author Contributions: Conceptualization, A.C.; Data curation, G.D., N.N. and L.N.; Formal analysis, A.C. and A.B.; Investigation, G.D., A.S. and A.C.; Methodology, A.C. and N.L.; Software, A.C.; Validation, G.D., A.S. and A.B.; Visualization, A.S.; Writing-review \& editing, A.C., A.B., A.S. and G.D.

Funding: This research received no external funding.

Acknowledgments: This research received no external funding. It was carried out thanks to soil and meteorological data, as well as data on irrigation volumes, provided by the Consorzio di Bonifica della Capitanata, Foggia, Italy. We are especially grateful to Pandi Zdruli of the IAMB, as well as to Osvaldo Moro and his collaborators of the $\mathrm{CBC}$ for their work on the field pedological and hydrological experiments and investigations.

Conflicts of Interest: The authors declare no conflict of interest.

\section{Appendix A. FLOWS-HAGES: Short Model Description}

\section{Appendix A.1. Water Flow}

One-dimensional vertical transient water flow in this model is simulated by numerically solving the 1D form of the Richards equation (Equation (A1)) using an implicit, backward, finite differences scheme with explicit linearization similar to that adopted in the Soil-Water-Atmosphere-Plant (SWAP) model [23]:

$$
C(h) \frac{\partial h}{\partial t}=\frac{\partial}{\partial z}\left(K(h) \frac{\partial h}{\partial z}-K(h)\right)-S_{w}(h)
$$

where $C(h)=d \theta / d h\left(\mathrm{~L}^{-1}\right)$ is the soil water capacity, $h(\mathrm{~L})$ is the soil water pressure head, $t(\mathrm{~T})$ is time, $z$ $(\mathrm{L})$ is the vertical coordinate being positive upward, $K(\mathrm{~h})\left(\mathrm{L} \cdot \mathrm{T}^{-1}\right)$ the hydraulic conductivity and $S_{w}(h)$ $\left(\mathrm{T}^{-1}\right)$ is a sink term describing water uptake by plant roots. 


\section{Appendix A.2. Solute Transport}

The advection-dispersion equation (ADE) is used for prediction of solute transport (agrochemicals, salts, heavy metals, ... ):

$$
\frac{\partial \theta C}{\partial t}+\rho_{b} \frac{\partial Q}{\partial t}=\frac{\partial q C}{\partial z}+\frac{\left(\partial \theta D \frac{\partial C}{\partial z}\right)}{\partial z}-S_{s}
$$

Including non-linear adsorption, linear decay and proportional root uptake in unsaturated/saturated soil. In the equation, $C\left(\mathrm{M} \cdot \mathrm{T}^{-3}\right)$ and $Q\left(\mathrm{M} \cdot \mathrm{M}^{-1}\right)$ are the amount of solute in the liquid and adsorbed phases, respectively, $q\left(\mathrm{~L} \mathrm{~T}^{-1}\right)$ is the darcian flux, $\rho_{b}\left(\mathrm{M} \mathrm{L}^{-3}\right)$ is the bulk density, $D\left(\mathrm{~L}^{2} \mathrm{~T}^{-1}\right)$ the hydrodynamic dispersion coefficient. $S_{s}$ is a source-sink term for solutes. Hydrodynamic dispersion is related to the molecular diffusion constant of the substance in bulk water, $D_{0}\left(\mathrm{~L}^{2} \mathrm{~T}^{-1}\right)$, and the pore water velocity, $v=q / \theta$, as:

$$
D=\lambda v+\eta(\theta) D_{0}
$$

where $\lambda(\mathrm{L})$ is the dispersivity and $\eta$ a tortuosity coefficient. However, as discussed by several researchers ([24,25], among others) the contribution of diffusion to the hydrodynamic dispersion $D$ is often very small. Accordingly, in this study $\lambda$ was simply derived from the ratio $D / v$.

\section{Appendix A.3. Hydraulic Properties}

Several water retention and hydraulic conductivity functions can be selected in the model. Water retention: Unimodal van Genuchten model [26]:

$$
\left\{\begin{array}{c}
S_{e}=\frac{\theta-\theta_{r}}{\theta_{s}-\theta_{r}}=\left[1+\left|\alpha_{V G} h\right|^{n}\right]^{-m}, h<0 \\
\theta=\theta_{s}, h 0
\end{array}\right.
$$

where $h$ is the pressure head $(h \leq 0), S_{e}$ is effective saturation and $\theta$ is the water content $\left(\theta_{s}\right.$ and $\theta_{r}$ are the water content at $h=0$ and for $h \rightarrow \infty$, respectively). $\alpha_{V G}\left(\mathrm{~cm}^{-1}\right), n$ and $m=1-1 / n$ are shape parameters. Note the effective saturation, $S_{e}$, is to be considered as a cumulative distribution function of pore size with a density function $f(h)$ which may be expressed by:

$$
f(h)=\frac{d S e}{d h}
$$

In natural soils, the presence of aggregates frequently results in a retention function curve having at least two points of inflection. To represent such behavior, a double porosity approach can be used which assumes that the pore space from $\theta_{r}$ to $\theta_{s}$ consists of two $f_{i}(h)$ distributions obtained by Equation (A5), each occupying a fraction $\phi_{i}$ of that pore space. Bimodal Durner model [27]:

$$
S_{e}=\sum \varphi_{i}\left[\frac{1}{1+\left(\alpha_{i} h\right)^{n_{i}}}\right]^{m_{i}}, 0<\varphi_{i}<1 \text { and } \sum \varphi_{i}=1 i=1,2
$$

in which $\phi_{i}$ is the weighting of the total pore space fraction to be attributed to the $i$ th subcurve, and $\alpha_{i}, n_{i}$ and $m_{i}$ still represent the fitting parameters for each of the partial curves. Bimodal Ross and Smettem model [28]:

$$
S_{e}=\varphi_{1}\left(1+\alpha_{1} h\right) \exp \left(-\alpha_{1} h\right)+\varphi_{2}\left[\frac{1}{1+\left(\alpha_{2} h\right)^{n_{2}}}\right]^{m_{2}}, 0<\varphi_{i}<1 \text { and } \sum \varphi_{i}=1 \quad i=1,2
$$

where the following simple one-parameter function:

$$
S_{e}=(1+\alpha h) \exp (-\alpha h)
$$


describes macroporosity in aggregated soils.

Hydraulic conductivity: Mualem's model is based on the capillary bundle theory [29] and relates relative hydraulic conductivity, $K_{r}$, to $f(h)$ by the equation:

$$
K_{r}(h)=\frac{K(h)}{K_{0}}=S_{e}^{\tau}[\eta(h) / \eta(0)]^{2}, \eta(h)=\int_{-\infty}^{\infty} h^{-1} f(h) d h
$$

in which $K_{0}$ is the hydraulic conductivity at $h=0$, and $\tau$ is a parameter accounting for the dependence of the tortuosity and the correlation factors on the water content.

For the case of the van Genuchten unimodal soil water retention model and assuming $m=1-1 / n$, Equation (A9) becomes [26]:

$$
K_{r}\left(S_{e}\right)=\frac{K\left(S_{e}\right)}{K_{0}}=S_{e}^{\tau}\left[1-\left(1-S_{e}^{\frac{1}{m}}\right)^{m}\right]^{2}
$$

For the bimodal case, Equation (A10) becomes:

$$
K_{r}(h)=\frac{K(h)}{K_{0}}=S_{e}^{\tau}\left[\sum_{i=1}^{2} \varphi_{i} \eta_{i}(h) / \sum_{i=1}^{2} \varphi_{i} \eta_{i}(0)\right]^{2}
$$

with parameters as defined earlier.

In the case of bimodal Durner water retention, the Equation (A11) becomes [30]:

$$
K_{r}\left(S_{e}\right)=\frac{K\left(S_{e}\right)}{K_{0}}=\left(\sum_{i=1}^{2} \varphi_{i} S_{e, i}\right)^{\tau}\left\{\frac{\sum_{i=1}^{2} \varphi_{i} \alpha_{i}\left[1-\left(1-S_{e, i}^{1 / m_{i}}\right)^{m_{i}}\right]}{\sum_{i=1}^{2} \varphi_{i} \alpha_{i}}\right\}^{2}
$$

For the Ross and Smettem model, the $\eta(h)$ functions in Equation (A9) are [28]:

$$
\eta_{1}(h)=\alpha_{R S} \exp \left(\alpha_{R S} h\right), \quad \eta_{2}(h)=\alpha_{V G} n B\left(S_{e}{ }^{1 / m}, m+1 / n, 1-1 / n\right)
$$

where $B()$ is the incomplete beta function.

Equation (A11) assumes that all pores in the material can interact [28].

In this case, an instantaneous equilibrium (i.e., instantaneous exchange of water) between the two pore systems is implicitly assumed. Nevertheless, for some materials part of the pore space may bypass the rest. This is the case when, for example, the cutans on the walls of the aggregates reduces the water transport between intra and inter-aggregate spaces. The conductivities of the two porous spaces are in parallel and, for such independent distributions, the following equations apply:

$$
k(h)=\sum_{i=1}^{2} k_{0 i} k_{r i}(h), \quad k_{r i}(h)=S_{e}^{\tau}\left[p_{i}(h) / p_{i}(0)\right]^{2}
$$

\section{Appendix A.4. Root Uptake}

According to the approach of Feddes [31], the (i) root system distribution and (ii) the activity of the roots along the root zone during the growth season, are embedded in the macroscopic sink term as follows:

(i) The potential root water uptake flux per unit depth at a specific depth, $S_{p}\left(\mathrm{~d}^{-1}\right)$, is simulated macroscopically by distributing potential transpiration, $T_{p}\left(\mathrm{~cm} \cdot \mathrm{d}^{-1}\right)$, over the root zone depth, $D r(\mathrm{~cm})$, on the basis of a normalized root density distribution, $g(z)\left(\mathrm{cm}^{-1}\right)$, with depth $\mathrm{z}$. The normalized root 
density distribution may be obtained by normalizing the root length density distribution $R_{l d}\left(\mathrm{~cm} \cdot \mathrm{cm}^{-1}\right)$ by its integral across the rooting depth, Dr:

$$
g(z)=\frac{R_{l d}(z)}{\int_{0}^{D r} R_{l d}(z) d z}
$$

$R_{l d}$ may be calculated as the ratio of the total length, $\operatorname{Lr}(z)$, of roots in a sample to the sample volume. Hereafter, we will define the denominator of Equation (A2) as root length density integral, $R_{I n t} \cdot g(z) d z$ is the fraction of roots located between $\mathrm{z}$ and $\mathrm{z}+\mathrm{dz}$. In the macroscopic approaches to root uptake, the function $g(z)$ distributes the potential transpiration rate, $T_{p}$, through the root zone in proportion to the root distribution [31,32]:

$$
S_{p}(z)=g(z) T_{p}
$$

with

$$
\int_{0}^{D r} g(z) d z=1
$$

and thus

$$
T_{p}=\int_{0}^{D r} S_{p}(z) d z
$$

(ii) Low water contents and/or the presence of soluble salts in the soil lower the total hydraulic head and may reduce the water fluxes to the roots, thus reducing root activity and water uptake. Reduction coefficients to decrease the maximum water uptake according to the water and osmotic stresses may be calculated independently and multiplied to calculate the actual root uptake as:

$$
S_{a}=\alpha_{r w}(h) \alpha_{r s}\left(h_{o}\right) S_{p}=\alpha_{r w}(h) \alpha_{r s}\left(h_{o}\right) g(z) T_{p}
$$

with $\alpha_{r w}$ and $\alpha_{r s}$ being reduction factors depending on the local (at a given $\mathrm{z}$ ) water pressure head, $h$ $(\mathrm{cm})$ and osmotic head, $h_{0}(\mathrm{~cm})$, respectively.

Accordingly,

$$
T_{a}=\int_{0}^{D r} S_{a}(z) d z
$$

and

$$
\frac{T_{a}}{T_{p}}=\int_{0}^{D r} g(z) \alpha_{r w}(h) \alpha_{r s}\left(h_{o}\right) d z=\beta\left(h, h_{0}\right)
$$

with $T_{a}$ being the actual transpiration rate and $\beta$ a dimensionless water stress index integrated over the whole rooted profile [33,34], providing a measure of total plant stress. A value of $\beta$ equal to 1 indicates that there is no stress in the soil root zone and that the actual transpiration rate $T_{a}$ is equal to the potential transpiration rate $T_{p}$.

When the soil is irrigated by keeping soil water content under optimal conditions, the eventual reduction in root uptake may only be induced by osmotic stress. Under only osmotic stresses, $\alpha_{r w}=1$ and root uptake parameterization reduces to finding the factor $\alpha_{r s}$, depending on the osmotic potential $\left(h_{0}\right)$ induced by salts in the soil water.

\section{Appendix A.5. Calculating the Water Stress Reduction Factor $\alpha_{r w}$}

Feddes and Raats [32] reviewed various functional forms for $\alpha_{r w}$ that have been proposed over the years. We mention here two general model types that have been used most often: piecewise linear functions and continuous smooth functions. To describe water stress, Feddes [31] proposed a 
piecewise linear reduction function parameterized by four critical values of the water pressure head, $h_{4}<h_{3}<h_{2}<h_{1}$ :

$$
\alpha_{r w}(h)=\left\{\begin{array}{c}
\frac{h-h_{4}}{h_{3}-h_{4}}, h_{3}>h>h_{4} \\
1, h_{2} \geq h \geq h_{3} \\
\frac{h-h_{1}}{h_{2} h_{1}}, h_{1}>h>h_{2} \\
0, h \leq h_{4} \text { or } h \geq h_{1}
\end{array}\right.
$$

Uptake is at the potential rate when the pressure head is $h_{3} \leq h \leq h_{2}$, drops off linearly when $h>$ $h_{2}$ or $h<h_{3}$, and becomes zero when $h \leq h_{4}$ or $h \geq h_{1}$. In general, the value of $h_{3}$ is expected to be a function of evaporative demand.

van Genuchten [35] proposed an alternative smooth, S-shaped reduction function to account for water stress:

$$
\alpha_{r w}(h)=\frac{1}{1+\left(\frac{h}{h_{50}}\right)^{p_{1}}}
$$

where $h_{50}$ and $p_{1}$ are adjustable parameters. Equation (A23) was motivated by a study [36] that found that an S-shaped function described salt tolerance yield reduction data better that other functions, including the threshold-slope model of Maas and Hoffman [37].

van Genuchten [35] reasoned that if water and salinity stress are assumed to have similar effects on yield, and hence on transpiration, then the S-shaped function should also be applicable to water stress response data.

\section{Appendix A.6. Calculating the Salinity Stress Reduction Factor $\alpha_{r s}$}

Despite the large body of studies on the topic (see amongst others [32,36,38-41]), proper modeling and parameterization of root water uptake as a function of salinity stresses remains a major challenge. The process is mainly determined by the specific soil-water-salt conditions and distributions which become established in the root zone according to the local soil physical-hydrological characteristics. This is why the well-known salt tolerance database presented by the U.S. Salinity Laboratory [37] should be handled with prudence in numerical modeling as most of those data were collected under well-controlled experimental conditions in which uniform salt distribution over the root zone was established. As confirmed by several researchers [34,38-41], the reduction function to be used in numerical modeling should be determined by analyzing the dynamics of water uptake under transient salinity conditions.

Several functional forms have been proposed for uptake reduction due to salinity (see amongst others [32,36]). The response function can be written in terms of concentration, or electrical conductivity of either the soil water or the soil saturation extract, or osmotic pressure head [36,37,42-44].

In terms of osmotic pressure heads, $h_{0}$, consistent with the Mass and Hoffman [37] model for crop salt tolerance (Equation (A6)), the effects of salinity stress on root water uptake can be described using the piecewise linear (threshold-slope) function:

$$
\alpha\left(h_{0}\right)= \begin{cases}1, & a \leq h_{o} \leq 0 \\ 1+b\left(h_{0}-a\right), & a>h_{o}>a-\frac{1}{b} \\ 0, & h_{o} \leq a-\frac{1}{b}\end{cases}
$$

where $a$ and $b$ are the adjustable parameters, often referred to as the salinity threshold and slope, respectively, thus mirroring the terminology used for the Maas-Hoffman parameters A and B. Note, however, that the parameter sets are not the same: A and B parameterize total yield reductions as a function of average root zone salinity, whereas $a$ and $b$ parameterize local reductions in the root water uptake rate as a function of osmotic head. 
Similarly, in correspondence to Equation (A4), a van Genuchten-Hoffman type model) for the effects of salinity stress on root water uptake can be described as an S-shaped salinity-stress function:

$$
\alpha_{r s}\left(h_{o}\right)=\frac{1}{1+\left(\frac{h_{0}}{h_{o, 50}}\right)^{p_{2}}}
$$

where $p_{2}$ and $h_{0,50}$ are the adjustable parameters, the latter being the osmotic pressure head where uptake is halved.

The osmotic potential, expressed as osmotic head $h_{0}$, is assumed to be a linear function of soil solution salinity $\mathrm{EC}_{\mathrm{w}}$ according to U. S. Salinity Laboratory Staff [45]:

$$
h_{0}=-360 E C
$$

Here, 360 is a factor to convert the salinity-based values to $\mathrm{cm}$ osmotic head.

\section{Appendix A.7. Combined Water and Salinity Stress}

A major challenge is how to combine the effects of water and salinity stress. Uptake reductions due to a combination of water and salinity stresses could be modeled by assuming that the stresses are somehow additive or multiplicative. A generalized model for additive stresses is obtained by assuming that water uptake occurs in response to some weighted sum of the soil water pressure and osmotic heads:

$$
\alpha_{r c}\left(h, h_{0}\right)=\frac{1}{1+\left[\frac{\alpha_{r w} h+\alpha_{r s} h_{0}}{h_{050}}\right]^{p_{2}}}
$$

with simple additivity resulting when $\alpha_{r w}=\alpha_{r s}=1$. Although additivity has been inferred from a number of laboratory and field experiments (e.g., [46-50]), its general applicability remains uncertain [51], especially for field conditions subject to relatively wide ranges in pressure heads (wetting/drying cycles).

Linear or weighted additivity is only one of several possibilities for combining the effects of water and salinity stress. Another approach presumes that water and salinity effects are multiplicative. In the general case this leads to:

$$
\alpha_{r c}=\alpha_{r w} \alpha_{r s}
$$

where $\alpha_{r w}$ and $\alpha_{r s}$ can be calculated as described above. In this case, Equation (A27) becomes:

$$
\alpha_{r c}\left(h, h_{0}\right)=\frac{1}{1+\left(\frac{h}{h_{50}}\right)^{p_{1}}} \times \frac{1}{1+\left(\frac{h_{0}}{h_{050}}\right)^{p_{2}}}
$$

where $h_{50}, p_{50}, p_{1}$ and $p_{2}$ are the presumably crop, soil and climate-specific parameters.

\section{Appendix A.8. Root Density Distribution}

Several root density distributions, $\mathrm{g}(\mathrm{z})$, may be dealt with in the model for simulating the sink term in Equation (A1), assuming root distributions to be either homogeneous [31] or variable with depth [52-54], the latter accounting for the fact that in a moist soil the roots can mainly extract water from the upper root zone layers.

A constant distribution over the whole root zone would reduce simply to [31]:

$$
g(z)=\frac{1}{D r}
$$

The model may also apply a modified version of the constant distribution in the case of layered root systems (see [55]). 
A Prasad-type triangular $g(z)$ function [52], with root water uptake at the bottom of the root zone $(D r)$ equal to zero:

$$
g(z)=\frac{2(D r-z)}{D r^{2}}
$$

A logistic root density distribution may also be used in the code

$$
g(z)=\frac{a b c \exp (c z)}{b+\exp (c z)^{2}}
$$

with $\mathrm{a}, \mathrm{b}$ and $\mathrm{c}$ being empirical parameters to be estimated by fitting the logistic to measured values of $g(z)$.

\section{Appendix A.9. Solute Sink Term}

The solute sink term $S_{s}$ is:

$$
S_{s}=\mu\left(\theta C+\rho_{b} Q\right)-R_{p f} S_{w} C
$$

where $\mu$ is the first order rate coefficient of transformation $\left(\mathrm{T}^{-1}\right), R_{p f}$ is the root uptake preference factor (dimensionless) accounting for positive or negative selection of solute ions relative to the amount of soil water that is extracted [23].

\section{References}

1. Blinda, M.; Thivet, G. Ressources et demandes en eau en Méditerranée: Situation et perspectives. Sécheresse 2009, 20, 9-16. [CrossRef]

2. Hsiao, T.; Steduto, P.; Fereres, E. A systematic and quantitative approach to improve water use efficiency in agriculture. Irrig. Sci. 2007, 25, 209-231. [CrossRef]

3. Lamaddalena, N.; Sagardoy, J. Performance Analysis of On-Demand Pressurized Irrigation Systems; Food \& Agriculture Organization of the United Nations: Rome, Italy, 2000. [CrossRef]

4. Coppola, A.; Comegna, V.; Basile, A.; Lamaddalena, N.; Severino, G. Darcian preferential water flow and solute transport through bimodal porous systems: Experiments and modelling. J. Contam. Hydrol. 2009, 104, 74-83. [CrossRef]

5. Coppola, A.; Randazzo, L.A. MatLab code for the transport of water and solutes in unsaturated soils with vegetation. In Tech. Rep. Soil and Contaminant Hydrology Laboratory; University of Basilicata: Potenza, Italy, 2006, unpublished work.

6. Coppola, A.; Randazzo, L.; Basile, A.; Fenu, C. FLOWS-HAGES (FLOw of Water and Solutes in Heterogeneous AGri-Environmental Systems): A MatLab Code for the Transport of Water and Solutes in Unsaturated Soils with Vegetation in Heterogenous Systems; D. S. U. o. B. Tech. Rep. Soil and Contaminant Hydrology Laboratory: Potenza, Basilicata, Italy, 2018, in press.

7. Vogel, T. SWM II-Numerical Model of Two-Dimensional Flow in a Variably Saturated Porous Medium; Wageningen Agricultural University: Wageningen, The Netherlands, 1988.

8. Gee, G.W.; Or, D. Particle-size analysis. In Methods of soil analysis, Part4. Physical methods. Soil Sci. Soc. Am. Book Ser. 2002, 5, 255-293.

9. Ankeny, M.; Ahmed, M.; Kaspar, T.; Horton, R. Simple Field Method for Determining Unsaturated Hydraulic Conductivity. Soil Sci. Soc. Am. J. 1991, 55, 467-470. [CrossRef]

10. Coppola, A.; Basile, A.; Wang, X.; Comegna, V.; Tedeschi, A.; Mele, G.; Comegna, A. Hydrological behaviour of microbiotic crusts on sand dunes: Example from NW China comparing infiltration in crusted and crust-removed soil. Soil Till. Res. 2011, 117, 34-43. [CrossRef]

11. Basile, A.; Buttafuoco, G.; Mele, G.; Tedeschi, A. Complementary techniques to assess physical properties of a fine soil irrigated with saline water. Environ. Earth Sci. 2012, 66, 1797-1807. [CrossRef]

12. Lazarovitch, N.; Ben-Gal, A.; Šimůnek, J.; Shani, U. Uniqueness of soil hydraulic parameters determined by a combined Wooding inverse approach. Soil Sci. Soc. Am. J. 2007, 71, 860-865. [CrossRef]

13. Šimůnek, J.; van Genuchten, M.T.; Sejna, M. The DISC Computer Software for Analyzing Tension Disc Infiltrometer Data by Parameter Estimation; Version 1.0; US Salinity Laboratory: Riverside, CA, USA, 2000. 
14. Reynolds, D.; Elrick, D. Saturated and field-saturated water flow parameters: Falling head soil core (tank) method. Methods of Soil Analysis, Part 4. Phys. Methods 2002, 5, 809-812.

15. Dane, J.H.; Hopman, J.W. Water retention and storage. In Methods of Soil Analysis: Part 4_Physical Methods; Dane, J.H., Topp, G.C., Eds.; Soil Science Society of America: Madison, WI, USA, 2002; pp. 721-738. [CrossRef]

16. Rhoades, J.D.; Corwin, D.L. Soil electrical conductivity: Effects of soil properties and application to soil salinity appraisal. Commun. Soil Sci. Plant Anal. 1990, 21, 837-860. [CrossRef]

17. Coppola, A.; Smettem, K.R.; Ajeel, A.; Saeed, A.; Dragonetti, G.; Comegna, A.; Lamaddalena, N.; Vacca, A. Calibration of an electromagnetic induction sensor with time-domain reflectometry data to monitor rootzone electrical conductivity under saline water irrigation. Eur. J. Soil Sci. 2016, 67, 737-748. [CrossRef]

18. Dragonetti, G.; Comegna, A.; Ajeel, A.; Deidda, G.P.; Lamaddalena, N.; Rodriguez, G.; Vignoli, G.; Coppola, A. Calibrating electromagnetic induction conductivities with time-domain reflectometry measurements. Hydrol. Earth Syst. Sci. 2018, 22, 1509-1523. [CrossRef]

19. Kachanoski, R.G.; Wesenbeeck, I.V.; Gregorich, E.G. Estimating spatial variations of soil water content using noncontacting electromagnetic inductive methods. Can. J. Soil Sci. 1988, 68, 715-722. [CrossRef]

20. Kachanoski, R.G.; Wesenbeeck, I.V.; Jong, E.D. Field scale patterns of soil water storage from non-contacting measurements of bulk electrical conductivity. Can. J. Soil Sci. 1990, 70, 537-542. [CrossRef]

21. Sheets, K.R.; Hendrickx, J.M. Noninvasive soil water content measurement using electromagnetic induction. Water Resour. Res. 1995, 31, 2401-2409. [CrossRef]

22. Evett, S.R.; Tolk, J.A.; Howell, T.A. Soil profile water content determination. Vadose Zone J. 2006, 5, 894-907. [CrossRef]

23. Van Dam, J.; Huygen, J.; Wesseling, J.G.; Feddes, R.A.; Kabat, P.; Van Walsum, P.E.; Groenendijk, P.; Van Diepen, C.A. Theory of SWAP, Version 2.0; Simulation of Water Flow, Solute Transport and Plant Growth in the Soil-Water-Atmosphere-Plant Environment; Technical Document; Wageningen Agricultural University: Wageningen, The Netherlands, 1998.

24. Comegna, V.; Coppola, A.; Sommella, A. Nonreactive solute transport in variously structured soil materials as determined by laboratory-based time domain reflectometry (TDR). Geoderma 1999, 92, 167-184. [CrossRef]

25. Vanderborght, J.; Vereecken, H. Review of Dispersivities for Transport Modeling in Soils. Vadose Zone J. 2007, 6, 29-52. [CrossRef]

26. Van Genuchten, M.T. A closed-form equation for predicting the hydraulic conductivity of unsaturated soils 1. Soil Sci. Soc. Am. J. 1980, 44, 892-898. [CrossRef]

27. Durner, W. Predicting the unsaturated hydraulic conductivity using multi-porosity water retention curves. Indirect Methods Estim. Hydraul. Prop. Unsaturated Soils 1992, 185-202.

28. Ross, P.J.; Smettem, K.R. Describing soil hydraulic properties with sums of simple functions. Soil Sci. Soc. Am. J. 1993, 57, 26-29. [CrossRef]

29. Mualem, Y. A new model for predicting the hydraulic conductivity of unsaturated porous media. Water Resour. Res. 1976, 12, 513-522. [CrossRef]

30. Priesack, E.; Durner, W. Closed-form expression for the multi-modal unsaturated conductivity function. Vadose Zone J. 2006, 5, 121-124. [CrossRef]

31. Feddes, R.A.; Kowalik, P.J.; Zaradny, J. Simulation of Field Water Use and Crop Yield; Centre for Agriculture Publishing and Documentation: Wageningen, The Netherland, 1978.

32. Feddes, R.A.; Raats, P.A.C. Parameterizing the soil-water-plant root system. Unsaturated Zone Model. Prog. Chall. Appl. 2004, 6, 95-141.

33. Jarvis, N.J. A simple empirical model of root water uptake. J. Hydrol. 1989, 107, 57-72. [CrossRef]

34. Shouse, P.J.; Ayars, J.E.; Šimůnek, J. Simulating root water uptake from a shallow saline groundwater resource. Agric. Water Manag. 2011, 98, 784-790. [CrossRef]

35. Van Genuchten, M.T. A Numerical Model for Water and Solute Movement in and Below the Root Zone; United States Department of Agriculture, Agricultural Research Service U.S. Salinity Laboratory: Riverside, CA, USA, 1987.

36. Van Genuchten, M.T.; Hoffman, G.J. Analysis of crop salt tolerance data. In Soil Salinity under Irrigation; Shainberg, I., Shalhevet, J., Eds.; Ecological Studies; Springer: Berlin/Heidelberg, Germany; New York, NY, USA, 1984; pp. 258-271.

37. Maas, E.V.; Hoffman, G.J. Crop salt tolerance-Current assessment. J. Irrig. Drain. Div. 1977, 103, 115-134. 
38. Skaggs, T.H.; van Genuchten, M.T.; Shouse, P.J.; Poss, J.A. Macroscopic approaches to root water uptake as a function of water and salinity stress. Agric. Water Manag. 2006, 86, 140-149. [CrossRef]

39. Homaee, M.; Dirksen, C.; Feddes, R.A. Simulation of root water uptake: I. Non-uniform transient salinity using different macroscopic reduction functions. Agric. Water Manag. 2002, 57, 89-109. [CrossRef]

40. Homaee, M.; Feddes, R.A.; Dirksen, C. Simulation of root water uptake: II. Non-uniform transient water stress using different reduction functions. Agric. Water Manag. 2002, 57, 111-126. [CrossRef]

41. Homaee, M.; Feddes, R.A.; Dirksen, C. Simulation of root water uptake: III. Non-uniform transient combined salinity and water stress. Agric. Water Manag. 2002, 57, 127-144. [CrossRef]

42. Maas, E.V. Salt tolerance of plants. Appl. Agric. Res. 1986, 1, 12-26.

43. Maas, E.V. Crop salt tolerance. In Agriculture Salinity Assessment and Management; Manuals and Reports on Engineering Practice; American Society Civil Engineers: New York, NY, USA, 1990; pp. 262-334.

44. Maas, E.V.; Grattan, S.R. Crop yields as affected by salinity. Agronomy 1999, 38, 55-110.

45. U.S. Salinity Laboratory Staff. Diagnosis and Improvement of Saline and Alkali Soils. USDA Handb.60; U.S. Govenment Printing Office: Washingtin, DC, USA, 1954.

46. Wadleigh, C.H. The integrated soil moisture stress upon a root system in a large container of saline soil. Soil Sci. 1946, 61, 219-238. [CrossRef]

47. Meiri, A.; Shalhevet, J. Crop growth under saline conditions. In Arid Zone Irrigation; Springer: Berlin/Heidelberg, Germany, 1973; pp. 277-290.

48. Childs, S.W.; Hanks, R.J. Model of Soil Salinity Effects on Crop Growth 1. Soil Sci. Soc. Am. J. 1975, 39, 617-622. [CrossRef]

49. Du Plessis, H.M. Evapotranspiration of citrus as affected by soil water deficit and soil salinity. Irrig. Sci. 1985, 6, 51-61. [CrossRef]

50. Bresler, E.; Hoffman, G.J. Irrigation Management for Soil Salinity Control: Theories and Tests 1. Soil Sci. Soc. Am. J. 1986, 50, 1552-1560. [CrossRef]

51. Shalhevet, J.; Hsiao, T.C. Salinity and drought. Irrig. Sci. 1986, 7, 249-264. [CrossRef]

52. Prasad, R. A linear root water uptake model. J. Hydrol. 1988, 99, 297-306. [CrossRef]

53. Raats, P.A.C. Steady Flows of Water and Salt in Uniform Soil Profiles with Plant Roots 1. Soil Sci. Soc. Am. J. 1974, 38, 717-722. [CrossRef]

54. Vrugt, J.A.; Hopmans, J.W.; Šimunek, J. Calibration of a two-dimensional root water uptake model. Soil Sci. Soc. Am. J. 2001, 65, 1027-1037. [CrossRef]

55. Coppola, A.; Comegna, A.; Dragonetti, G.; Gerke, H.H.; Basile, A. Simulated preferential water flow and solute transport in shrinking soils. Vadose Zone J. 2015, 14. [CrossRef] 